\title{
A novel defense mechanism that is activated on amyloid- $\beta$ insult to mediate cell survival: role of SGK1-STAT1/STAT2 signaling
}

\author{
WL Hsu ${ }^{1}$, TH Chiu ${ }^{1}$, DJC Tai ${ }^{2}$, YL Ma ${ }^{2}$ and EHY Lee ${ }^{\star, 2}$
}

Amyloid- $\beta(A \beta)$ is known to induce apoptotic cell death and its underlying mechanism has been studied extensively, but the endogenous protection mechanism that results from $A \beta$ insult is less known. In this study, we have found that $A \beta_{1-42}$ produced a dose-dependent decrease in cell viability and dose-dependent increase in apoptotic cell death in PC12 cells. Meanwhile, $A \beta_{1-42}$ $(0.1 \mu \mathrm{M})$ increased the phosphorylation of serum- and glucocorticoid-inducible kinase1 (SGK1) at Ser-78 specifically. A parallel increase in ERK1/2, STAT1 and STAT2 phosphorylation and the anti-apoptotic gene Mcl-1 expression was also observed. Transfection of rat siRNAs against ERK1/2, SGK1, STAT1 and STAT2 abolished these effects of A $\beta$. Transfection of sgkS78D, the constitutively active SGK1, dose-dependently protected against A $\beta$-induced apoptosis and dose-dependently increased the expression of Mcl-1. SGK1 activation further phosphorylates STAT1 at Tyr-701 and Ser-727 directly, and activates STAT2 at Tyr-690 indirectly. Phosphorylation of STAT1/STAT2 upregulated Mcl-1 expression which in turn protected against A $\beta$-induced apoptosis. But Mcl-1 siRNA transfection enhanced A $\beta$-induced apoptosis. Mutation of SGK1 at Ser-78 blocked the effect of $A \beta$ on STAT1/STAT2 phosphorylation and Mcl-1 expression. Further, mutation of STAT1/STAT2 prevented the effect of both A $\beta$ and SGK1 on Mcl-1 expression. These results together showed a novel endogenous protection mechanism that is activated on $A \beta$ insult to mediate cell survival.

Cell Death and Differentiation (2009) 16, 1515-1529; doi:10.1038/cdd.2009.91; published online 17 July 2009

The presence of senile plaque is a major pathological hallmark of Alzheimer's disease $(\mathrm{AD})$ and amyloid- $\beta$ peptides $\left(\mathrm{A} \beta_{1-40}\right.$, $\left.\mathrm{A} \beta_{1-42}\right)$ are the major components of senile plaque. $\mathrm{A} \beta$ is generated from sequential and proteolytic cleavage of the amyloid precursor protein (APP) by $\beta$ - and $\gamma$-secretases. ${ }^{1} \mathrm{~A} \beta$ is known to cause lipid peroxidation, free radical production, caspase-3 activation, protein cleavage and DNA fragmentation that finally lead to apoptosis. ${ }^{2-4} \mathrm{~A} \beta$ also promotes the expression of some pro-inflammatory genes, such as cyclooxygenase-2 and interleukin-1 $\beta$, and activation of these signalings would also result in apoptosis. ${ }^{5}$ Further, $\mathrm{A} \beta$ was shown to activate the p53 promoter and result in p53-dependent apoptosis. ${ }^{6}$ On the other hand, when $\mathrm{A} \beta$ produces its toxicity, cells would also develop defense mechanisms to cope with $\mathrm{A} \beta$ toxicity. For example, a nonamyloidogenic neurotrophic peptide $\operatorname{SAPP} \alpha$ is generated by $\alpha$-secretase cleavage of APP and SAPP $\alpha$ is shown to activate neuroprotectin D1 to promote cell survival. ${ }^{5}$ However, with the role and mechanism of $\mathrm{A} \beta$-induced toxicity been studied extensively, the endogenous rescue mechanism caused by $A \beta$ is less known.

Serum- and glucocorticoid-inducible kinase 1 (SGK1) is a member of the serine/threonine protein kinase family that is induced transcriptionally by glucocorticoid and serum ${ }^{7}$ and it governs a variety of cellular functions. ${ }^{8}$ SGK1 is a downstream target of phosphatidylinositol 3-kinase (PI3-K) signaling. ${ }^{9}$ SGK 1 is directly phosphorylated by 3 -phosphoinositide- dependent protein kinase 1 (PDK1) at Thr-256 on SGK1 phosphorylation by PDK2 at Ser-422. ${ }^{10}$ In addition, SGK1 is phosphorylated by $\mathrm{p} 38$ mitogen-activated protein kinase (p38 MAPK) at Ser-78 and p38 MAPK phosphorylation of SGK1 mediates cell survival in response to interleukin-6 stimulation. ${ }^{11}$ In another study, SGK1 was shown to promote cell survival through phosphorylation and inactivation of the proapoptotic forkhead transcription factor FKHRL1. ${ }^{12}$ Further, induction of SGK1 protects epithelial tumor cells from serum starvation-induced apoptosis. ${ }^{13}$ These results suggest that SGK1 has an important function in cell survival. However, whether SGK1 also mediates a survival signaling on $\mathrm{A} \beta$ stimulation and how does it mediate cell survival is not known.

Signal transducers and activators of transcription (STAT) factors are a family of transcription factors that mediate the effect of various cytokines, growth factors and hormones and regulate various cellular functions including cell growth, differentiation, apoptosis and development. ${ }^{14,15}$ STATs are believed to produce these effects through transcriptional regulation of gene expression on STAT phosphorylation at tyrosine, dimerization and translocation to the nucleus. ${ }^{16}$ Some STATs are also phosphorylated at the serine residue and STAT phosphorylation at serine was shown to enhance the transcriptional activity of STAT, such as STAT1 phosphorylation at Ser-727. ${ }^{17}$ STAT1 is implicated in the regulation

${ }^{1}$ Department of Physiology, National Yang-Ming University, Taipei and Taiwan; ${ }^{2}$ Division of Neuroscience, Institute of Biomedical Sciences, Academia Sinica, Taipei 115, Taiwan

${ }^{*}$ Corresponding author: EHY Lee, Institute of Biomedical Sciences, Academia Sinica, No. 128, Sec. 2, Academic Road, Taipei 115, Taiwan.

Tel: + 88622789 9125; Fax: + 88622782 9224; E-mail: eminy@ gate.sinica.edu.tw

Keywords: A $\beta_{1-42}$; ERK1/2; SGK1; STAT1; STAT2; Mcl-1; anti-apoptosis

Abbreviations: $\mathrm{A} \beta$, amyloid- $\beta$; SGK1, glucocorticoid-inducible kinase1; AD, Alzheimer's disease; PDK1, 3-phosphoinositide-dependent protein kinase 1; STAT, signal transducers and activators of transcription

Received 24.9.08; revised 22.5.09; accepted 09.6.09; Edited by L Greene; published online 17.7.09 
of apoptosis. ${ }^{18-20}$ For example, overexpression of STAT1 enhances apoptotic cell death in cardiac myocyte after ischemia-reperfusion, but STAT1 antisense manipulation reduces apoptosis and decreases STAT1-induced caspase 1 and apoptotic gene (FAS, FASL) promoter activity. ${ }^{21,22}$ Further, overexpression of STAT1 inhibits the promoter activity of anti-apoptotic genes $\mathrm{BCl}-2$ and $\mathrm{BCl}-{ }_{x L} \cdot{ }^{23}$ STAT1 also induces apoptosis through interacting with p53 and enhanced expression of p53-regulated genes. ${ }^{24}$ On the other hand, few recent studies showed that STAT1 could also be a survival factor. For example, STAT1 phosphorylation at Ser-727 by casein kinase 2 (CK2) is resistant to apoptosis in Wilms' tumor cells through upregulation of the expression of heat-shock protein 27 and myeloid cell leukemia (Mcl-1). ${ }^{25}$ In addition, increase in STAT1 and STAT1 phosphorylation plays a role in docetaxol resistance in prostate tumor cells through regulation of clusterin. ${ }^{26}$ To further elucidate the role of STAT1 involved in apoptosis, in this study we examined whether A $\beta$ activates STAT1 and whether STAT1 activation by $\mathrm{A} \beta$ mediates apoptosis or survival. We also examined the expression of the anti-apoptotic gene $\mathrm{Mcl}-1^{27,28}$ involved in $\mathrm{A} \beta$ toxicity. $\mathrm{A} \beta_{1-42}$ was used in this study. Our results revealed that $A \beta$ activates ERK1/2 and activates SGK1 at Ser-78 selectively. SGK1 activation further phosphorylates STAT1 at Tyr-701 and Ser-727 directly, and activates STAT2 at Ser-690 indirectly. This signaling cascade leads to increased expression of $\mathrm{Mcl}-1$ that protects against $\mathrm{A} \beta$-induced apoptosis.

\section{Results}

A $\beta$ induces apoptosis and enhances Mcl-1 expression for cell protection. Different concentrations of $\mathrm{A} \beta(0.01-$ $5.0 \mu \mathrm{M}$, dissolved in $1 \% \mathrm{DMSO}$ ) were added to PC12 cells and their effects on apoptotic cell death and $\mathrm{Mcl}-1$ expression were examined. Results from TUNEL (terminal deoxynucleotidyl transferase dUTP nick-end labeling) assay revealed that $A \beta$ produced a dose-dependent increase in apoptotic cell death $(P<0.01)$ (Figure $1 \mathrm{a}$ and $\mathrm{b})$. Meanwhile, moderate concentrations of $\mathrm{A} \beta(0.1$ to $1.0 \mu \mathrm{M})$ produced a dose-dependent increase in Mcl-1 mRNA expression (Figure 1c) and $\mathrm{Mcl}-1$ protein expression (Figure 1d) (both $P<0.01)$. These results suggest that $\mathrm{Mcl}-1$ expression induced by $\mathrm{A} \beta$ probably plays a protective role. To test this hypothesis, $\mathrm{Mcl}-1$ plasmid DNA $(0.1 \mu \mathrm{g})$ was transfected to PC12 cells $24 \mathrm{~h}$ before various concentrations of $\mathrm{A} \beta$ and cell viability was assessed. Results revealed that overexpression of $\mathrm{Mcl}-1$ partially inhibited the effect of $\mathrm{A} \beta(0.1-1.0 \mu \mathrm{M})$ on decrease in cell viability $(P<0.05$ or 0.01$)$ with the maximum effect observed for $0.1 \mu \mathrm{M} \mathrm{A} \beta(P<0.01)$ (Figure 1e). Thus, this concentration of $A \beta$ was used for future experiments. $\mathrm{Mcl}-1$ overexpression is not as effective against 0.5 and $1.0 \mu \mathrm{M} \mathrm{A} \beta$. This is probably because that $\mathrm{A} \beta$ at these concentrations causes a much higher degree of apoptosis to be effectively rescued. Transfection and expression of $\mathrm{Mcl}-1$ was confirmed by western blot against the Flag tag (Figure 1e, bottom). We next examined whether expression of $\mathrm{Mcl}-1$ indeed protects against $\mathrm{A} \beta$-induced apoptosis. Results from TUNEL assay revealed that $\mathrm{A} \beta$ significantly increased apoptotic cell death $(P<0.001)$, but this effect was partially inhibited by $\mathrm{Mcl}-1(0.1 \mu \mathrm{g})$ transfection $(P<0.01$ compared with $A \beta$ group) (Figure 1f). Transfection and expression of $\mathrm{Mcl}-1$ was confirmed by western blot against Flag (Figure 1f, bottom). On the other hand, interference of $\mathrm{Mcl}-1$ expression by transfection of Mcl-1 siRNA (1, 5 and 10 $\mathrm{pM})$ to $\mathrm{PC} 12$ cells potentiated $\mathrm{A} \beta$-induced decrease in cell viability in a dose-dependent manner $(P<0.01)$, whereas Mcl-1 siRNA transfection alone (10 pM) was without an effect (Figure 1g). The effectiveness of Mcl-1 siRNA transfection was confirmed by decreased $\mathrm{Mcl}-1$ protein level (Figure 1g, bottom). These results show that $\mathrm{A} \beta$-induced $\mathrm{Mcl}-1$ expression does play a protective role against $A \beta$-induced apoptosis. The following experiments examined the molecular mechanism underlying A $\beta$-induced $\mathrm{Mcl}-1$ expression and cell protection. Meanwhile, the reverse $\mathrm{A} \beta$ $\left(\mathrm{A} \beta_{42-1}\right)$ did not induce apoptosis in PC12 cells over a wide range of doses examined (Supplementary Figure S1).

A $\beta$ activates SGK1 at Ser-78 to mediate cell survival. In this experiment, we examined the protein kinase that mediates $\mathrm{A} \beta$ signaling to $\mathrm{Mcl}-1$. SGK1 was shown to mediate cell survival in response to various stress stimuli. We, therefore, examined the role of SGK1 here. A $\beta$ was added to PC12 cells and SGK1 activation was examined at various time points after $\mathrm{A} \beta(15,30,60,180$ and $360 \mathrm{~min})$. A representative gel pattern for $A \beta$ phosphorylation of SGK1 was shown in Figure 2a. Results revealed that $A \beta$ increased SGK1 phosphorylation at Ser-78 in a time-dependent manner with the maximum effect observed at $30 \mathrm{~min}$ $(P<0.01)$ (Figure 2b, upper). This effect declined $60 \mathrm{~min}$ later. But SGK1 phosphorylation at Thr-256 and Ser-422 was not affected by $\mathrm{A} \beta$ (Figure $2 \mathrm{~b}$, middle and lower). Meanwhile, $\mathrm{A} \beta$ increased the phosphorylation of extracellular signalregulated kinase $1 / 2(E R K 1 / 2)$ at a parallel time course or shortly before SGK1 Ser-78 phosphorylation $(P<0.05$ or $P<0.01$, Figure 2c). These results suggest that ERK $1 / 2$ phosphorylation may be related to SGK1 phosphorylation.

As SGK1 was activated by A $\beta$ at Ser-78, if SGK1 plays a protective role, then activation of SGK1 at Ser-78 should protect against $\mathrm{A} \beta$-induced toxicity. We tested this hypothesis here. Various constitutively active SGK1 including sgkS78D, sgkT256D, sgkS422D, the wild-type SGK1 (sgkWT) and kinase-dead SGK1 (sgkK127M) (1.6 $\mu \mathrm{g}$ each) were transfected to $\mathrm{PC} 12$ cells $24 \mathrm{~h}$ before $\mathrm{A} \beta$ treatment. Results revealed that $\mathrm{A} \beta$ decreased cell viability $(P<0.01)$; transfection of sgkWT alone did not have an effect, but transfection of $s g k W T$ and $s g k S 78 D$ both partially reduced this effect of $\mathrm{A} \beta$ (both $P<0.05$ compared with $\mathrm{A} \beta$ group) (Figure $2 \mathrm{~d}$ ). However, transfection of $s g k T 256 D$ and $s g k S 422 D$ was without such an effect $(P>0.05)$ (Figure 2d). To confirm that sgkWT and $s g k S 78 D$ do affect cell viability rather than cell proliferation, TUNEL assay was also carried out. Our results showed that both $s g k W T$ and $s g k S 78 D$ partially inhibited $A \beta$-induced apoptosis (Supplementary Figure S2), supporting the results obtained from MTT assay. To further examine the protective role of $s g k S 78 D$, different concentrations of $s g k S 78 D(0.4$, $0.8,1.6$ and $3.2 \mu \mathrm{g}$ ) were transfected to PC12 cells together with $\mathrm{A} \beta$. Results revealed that $\mathrm{A} \beta$ consistently decreased cell viability $(P<0.01)$, but $s g k S 78 D$ transfection reversed this effect of $\mathrm{A} \beta$ in a dose-dependent manner $(P<0.05$ or 


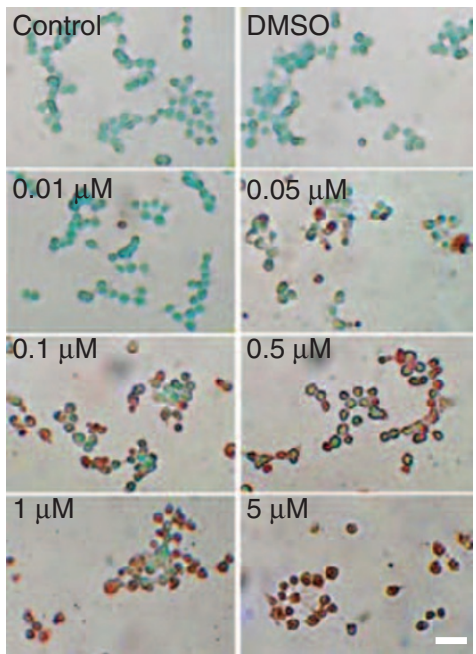

b

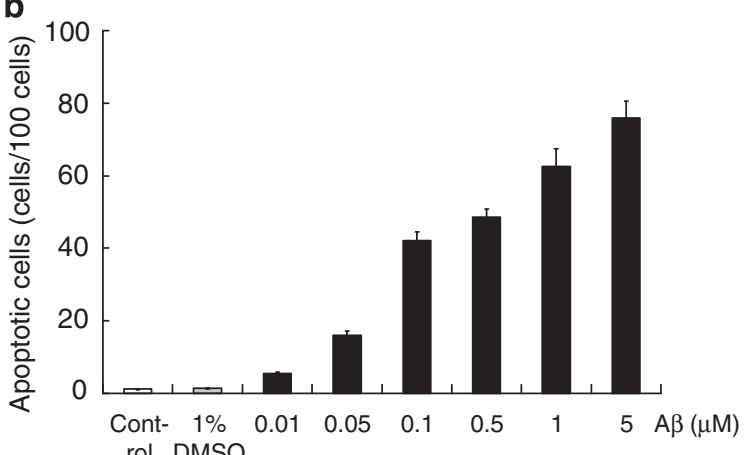
rol DMSO

\section{C}

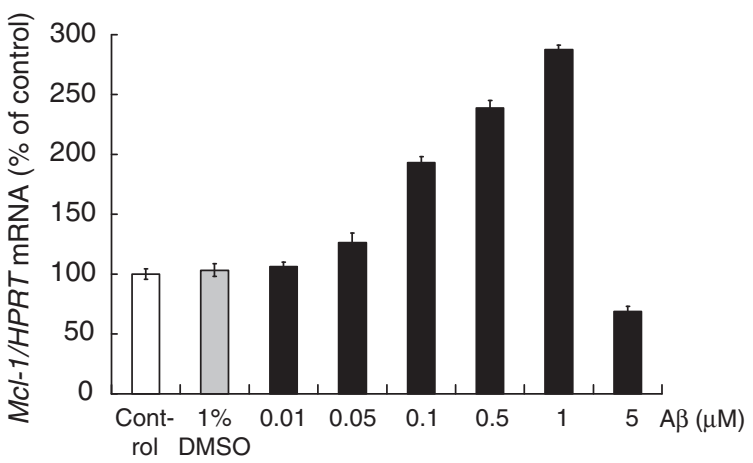

d rol DMSO

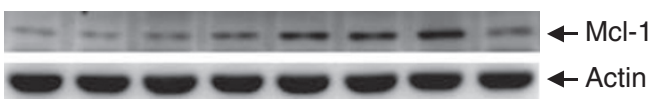

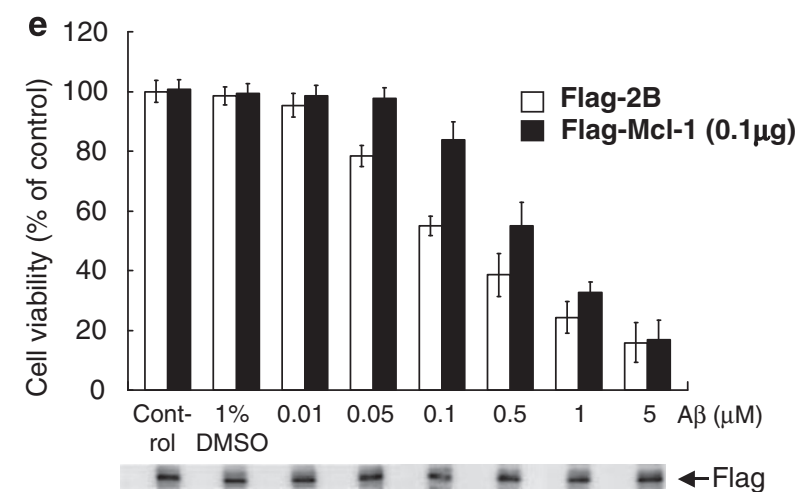

f $0.1 \mu \mathrm{M}$
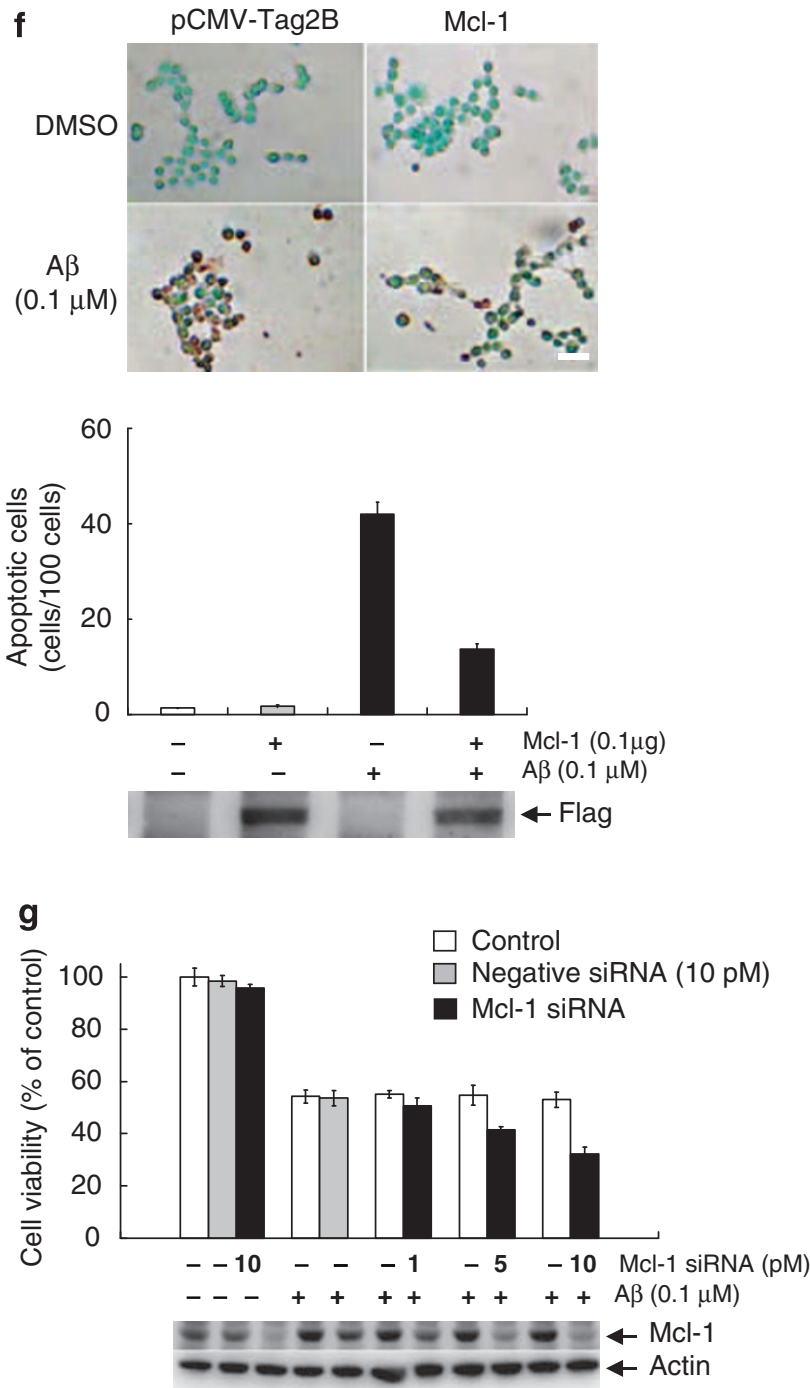

Figure 1 Upregulation of Mcl-1 expression induced by $\mathrm{A} \beta$ protects against $\mathrm{A} \beta$-induced apoptosis. $(\mathbf{a}, \mathbf{b})$ Induction of apoptosis by various concentrations of $\mathrm{A} \beta 24 \mathrm{~h}$ later. Apoptotic nucleus was detected by TUNEL staining (brown color) and quantified. (c) Mcl-1 mRNA level was measured by real-time PCR $24 \mathrm{~h}$ after various concentration of A $\beta$. (d) Mcl-1 protein level was measured by western blot $24 \mathrm{~h}$ after various concentrations of $\mathrm{A} \beta$. (e) Flag-Mcl-1 plasmid was transfected to PC12 cells $24 \mathrm{~h}$ before various concentrations of $A \beta$ and cell viability was assessed by MTT assay $24 \mathrm{~h}$ after $\mathrm{A} \beta$. Transfection and expression of Mcl-1 was confirmed by western blot against the Flag tag. (f) Apoptotic nucleus was evaluated by TUNEL staining and quantified $24 \mathrm{~h}$ after A $\beta$ and $48 \mathrm{~h}$ after $\mathrm{Mcl}-1$ plasmid $(0.1 \mu \mathrm{g})$ transfection. Transfection and expression of Mcl-1 was confirmed by western blot against Flag. (g) Different concentrations of Mcl-1 siRNA were transfected $24 \mathrm{~h}$ before A $\beta$ and cell viability was assessed by MTT assay $24 \mathrm{~h}$ after $\mathrm{A} \beta$. Mcl-1 siRNA transfection was confirmed by western blot against Mcl-1. Data are expressed as mean \pm S.E.M. Experiments were performed in triplicates. Scale $\operatorname{bar}=25 \mu \mathrm{m}$ 
$P<0.01$ ) (Figure 2e). As the effect of $A \beta$ and $s g k S 78 D$ on cell viability was confirmed by TUNEL assay earlier (Figure 1a; Supplementary Figure S2), it is not re-examined here.

We next examined whether SGK1 Ser-78 activation enhances $\mathrm{Mcl}-1$ expression. Different concentrations of sgkS78D $(0.4,0.8,1.6$ and $3.2 \mu \mathrm{g})$ and $s g k S 78 A(3.2 \mu \mathrm{g})$, the dominant negative sgk1, were transfected to PC12 cells and $\mathrm{Mcl}-1 \mathrm{mRNA}$ expression and protein expression were examined. Results revealed that sgkS78D enhanced $\mathrm{Mcl}-1$ mRNA expression in a dose-dependent manner $(P<0.05$ or $P<0.01)$, whereas $s g k S 78 A$ decreased $M c l-1$ mRNA expression $(P<0.01)$ (Figure 2f). The effectiveness of $s g k 1$ plasmid transfection and expression was confirmed by western blot against the HA tag (Figure 2f, bottom). Meanwhile, sgkS78D increased $\mathrm{Mcl}-1$ protein level in a dose-dependent manner, whereas $s g k S 78 A$ decreased $\mathrm{Mcl}-1$ protein level (Figure $2 \mathrm{~g}$ ).

As $A \beta$ is a deleterious stimulus that also activates stressinduced c-Jun-N-terminal kinase (JNK) activation and cell death, ${ }^{29}$ in this study, we examined whether $\mathrm{A} \beta$ treatment to PC12 cells would also activate JNK and whether $\mathrm{A} \beta$ activation of SGK1 may depend on $\mathrm{A} \beta$ activation of JNK. The JNK inhibitor SP600125 $(50 \mu \mathrm{M})$ was added to PC12 cells $30 \mathrm{~min}$ before $\mathrm{A} \beta$ and western blot was carried out $30 \mathrm{~min}$ after $\mathrm{A} \beta$ treatment. Results showed that $\mathrm{A} \beta$ consistently increased SGK1 phosphorylation at Ser-78. A $\beta$ also increased the phosphorylation level of JNK (mainly the upper band). However, prior SP600125 treatment inhibited A $\beta$-induced JNK phosphorylation, but it did not alter $A \beta$-induced SGK1

a
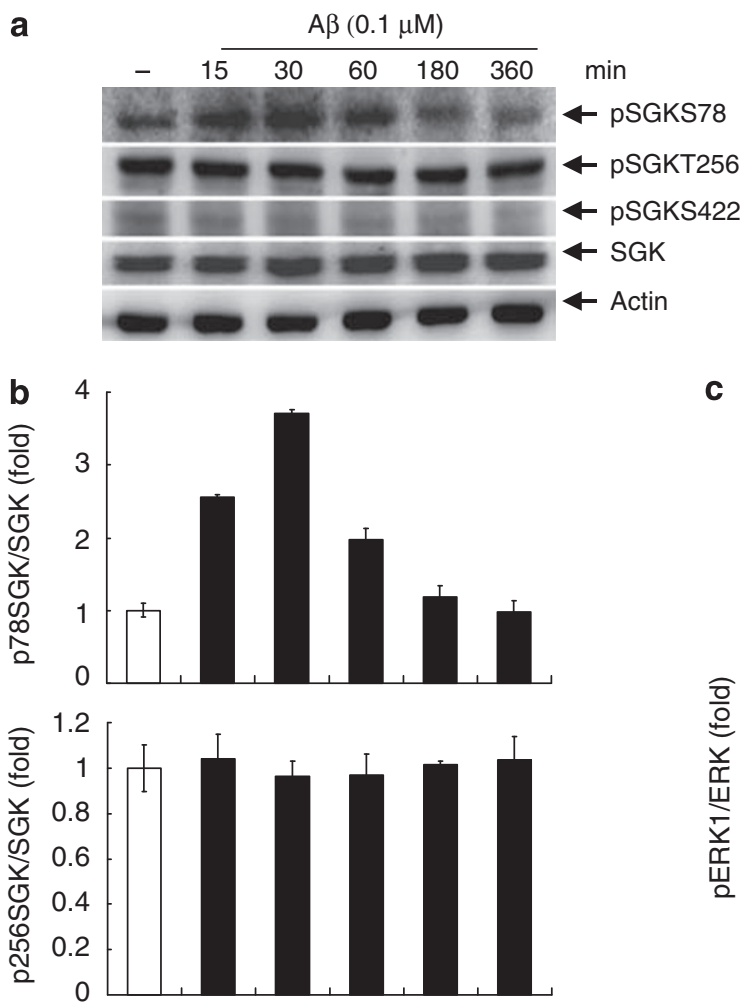

C
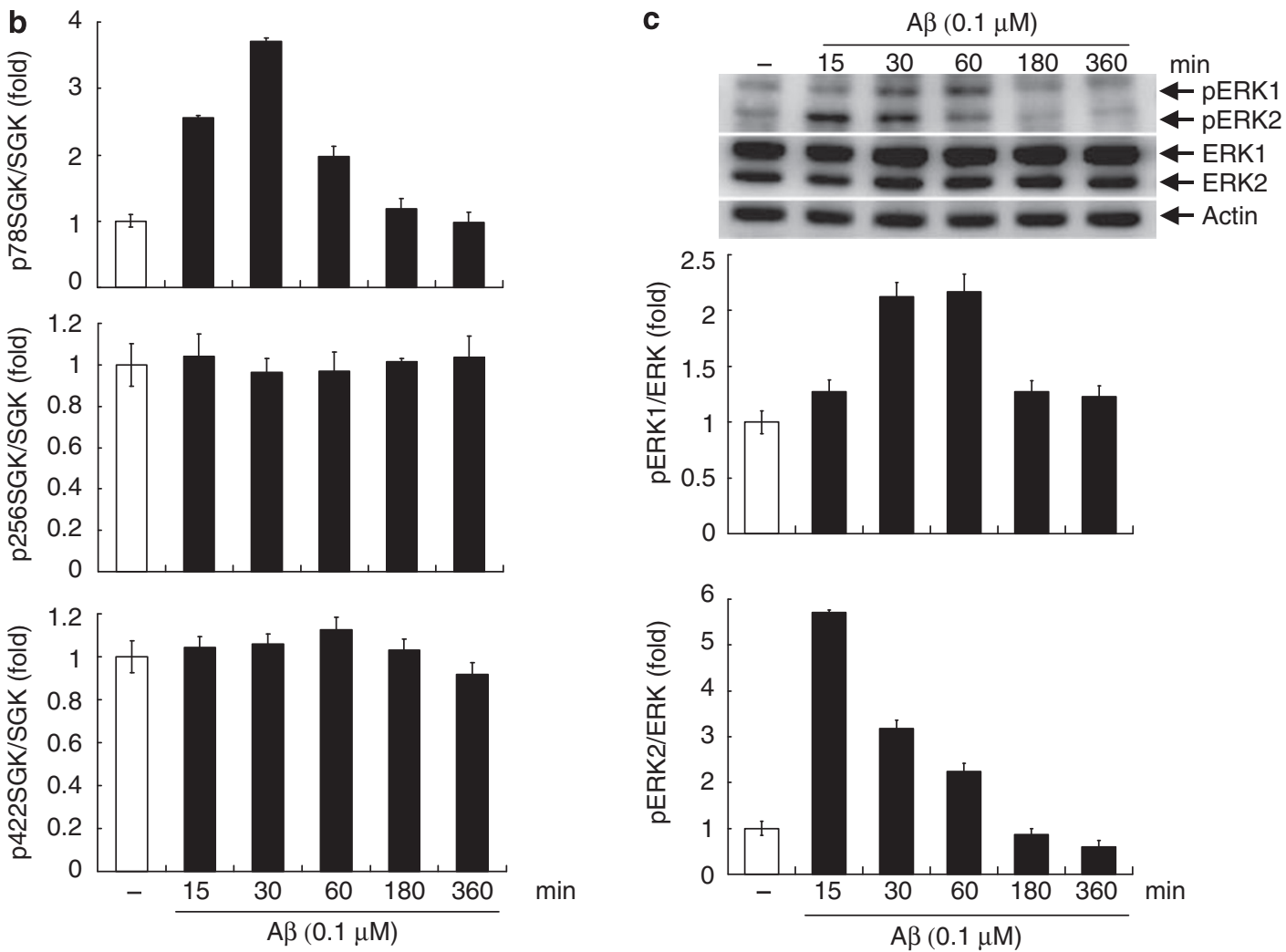

Figure 2 SGK1 Ser-78 was activated by A $\beta$ that increases Mcl-1 expression and protects against A $\beta$-induced decrease in cell viability. (a, b) SGK1 phosphorylation at Ser-78, Thr-256 and Ser-422 and (c) ERK1/2 phosphorylation was assessed by western blot and quantified at various time points after A $\beta$ treatment. (d) Cell viability was assessed by MTT assay $24 \mathrm{~h}$ after $\mathrm{A} \beta$ and $48 \mathrm{~h}$ after transfection with various sgk1 plasmid and the kinase-dead sgk1 plasmid. Transfection and expression of various sgk1 plasmids was confirmed by western blot against the HA tag. (e) Cell viability was assessed by MTT assay $24 \mathrm{~h}$ after $\mathrm{A} \beta$ and $48 \mathrm{~h}$ after transfection with various concentrations of $s g k S 78 D$ plasmid. Transfection and expression of $s g k S 78 D$ was confirmed by western blot against HA. (f) Mcl-1 mRNA level and (g) Mcl-1 protein level was measured $48 \mathrm{~h}$ after transfection with various concentrations of $s g k S 78 D$ plasmid or $s g k S 78 A$ plasmid. Transfection and expression of these $s g k 1$ plasmids was confirmed by western blot against HA. (h) The JNK inhibitor SP600125 was added to PC12 cells, alone or 30 min before A $\beta$, and that JNK phosphorylation and SGK1 phosphorylation at Ser-78 was measured 30 min after $A \beta$ by western blot. Data are expressed as mean \pm S.E.M. Experiments are in triplicates 

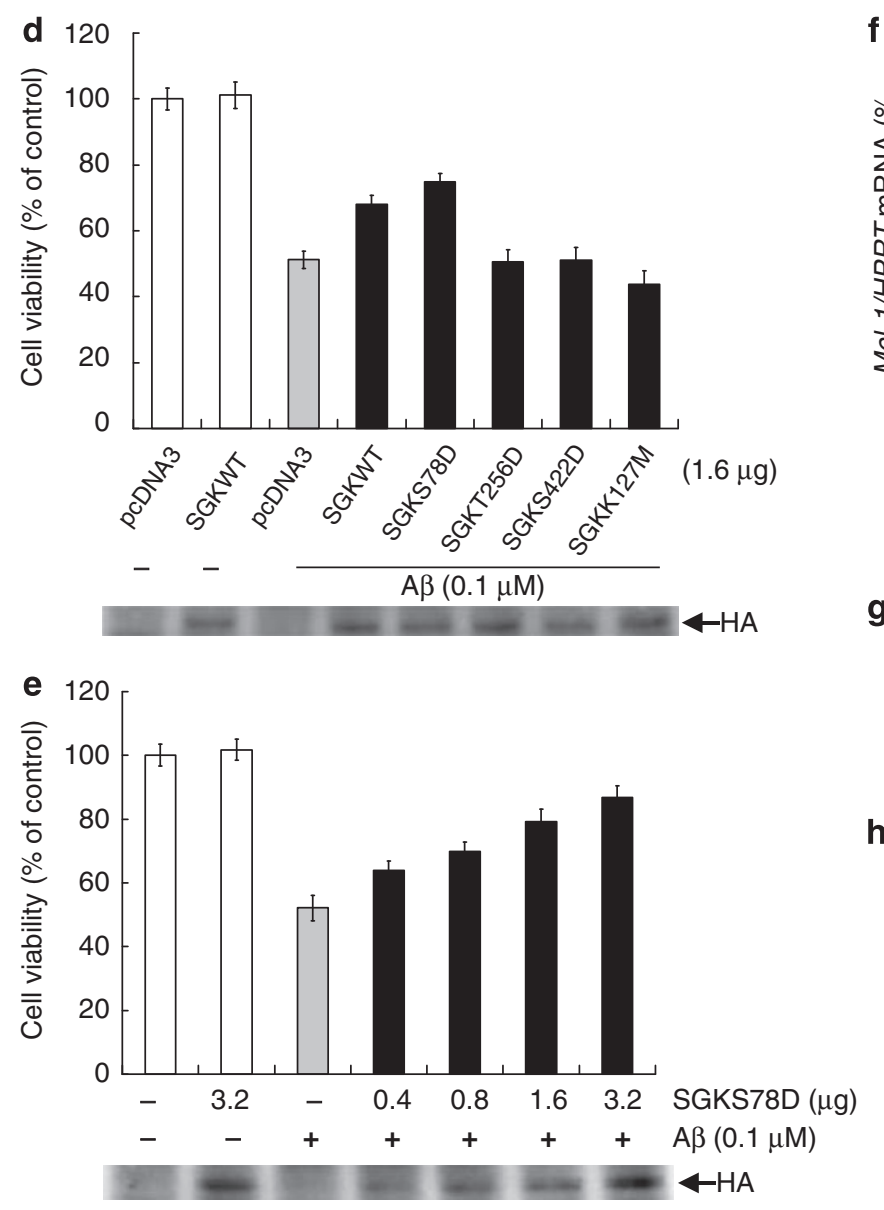

Figure 2 Continued.

phosphorylation at Ser-78 (Figure $2 \mathrm{~h}$ ). These results suggest that $\mathrm{A} \beta$ activation of SGK1 is independent of $\mathrm{A} \beta$ activation of $\mathrm{JNK}$.

SGK1 directly phosphorylates STAT1 and indirectly activates STAT2. The above results indicated that both $\mathrm{A} \beta$ and SGKS78D increased $\mathrm{Mcl}-1$ expression to enhance cell survival. We next examined the molecule downstream of SGK1 that regulates $M c l-1$ expression. In analyzing the promoter sequence of the $\mathrm{Mcl}-1$ gene, two ISRE elements (GAAANNNAAAC) were found from nucleotide -302 to -311 and -400 to -409 (Figure $3 a$ ). ISRE is the specific binding site for STAT1/STAT2 heterodimer, ${ }^{30}$ we therefore examined whether SGK1 may phosphorylate STAT1 and STAT2 to regulate $\mathrm{Mcl}-1$ expression. In vitro kinase assay using active SGK1 (10, 50 and $100 \mathrm{ng})$ and recombinant STAT1 revealed that SGK1 directly phosphorylates STAT1 in a dose-dependent manner (Figure $3 b$ ). Further western blotting indicated that SGK1 phosphorylates STAT1 at both Tyr-701 and Ser-727 (Figure 3b). We next examined whether SGK1 directly phosphorylates STAT1 at Tyr-701 and Ser-727. Active SGK1 and His-tagged STAT1 WT and mutant (STAT1Y701F, STAT1S727A) proteins were used. Results showed that SGK1 phosphorylates STAT1 at Tyr701 and Ser-727 directly (Figure 3c). Similar in vitro and in vivo kinase assays were conducted for active SGK1 (100 ng) and recombinant STAT2 with and without the

g

h
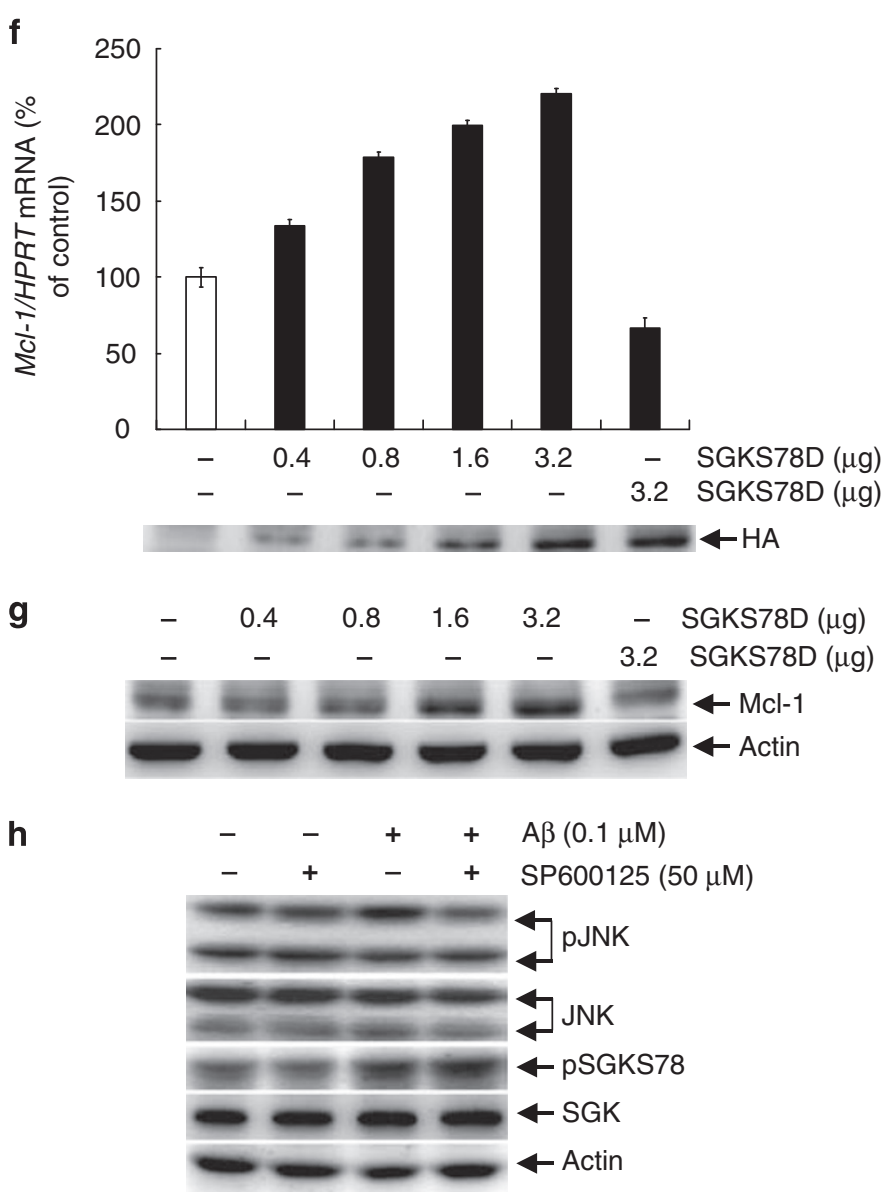

addition of PC12 cell lysate $(10 \mu \mathrm{g})$. Results revealed that there is a basal level of STAT2 phosphorylation by endogenous kinases in the lysate (comparing lane 1 and lane 2), but SGK1 does not further increase this phosphorylation level (comparing lane 2 and lane 3) (Figure 3d). In vitro kinase assay also showed that STAT2 is not a substrate for SGK1 (lanes 4-6, Figure 3d).

We next examined whether SGK1 is associated with STAT1 and STAT2. HA-SGK1 and Flag-STAT1 plasmids were co-transfected to HEK293T cells for immunoprecipitation and immunoblotting experiments. Results revealed that SGK1 is associated with STAT1 and vice versa (Figure 3e). Similar experiment was carried out for SGK1 and STAT2 by co-transfection of HA-SGK1 and V5-STAT2 plasmids to HEK293T cells. Results revealed that SGK1 is also associated with STAT2 and vice versa (Figure $3 f$ ).

We next examined whether SGK1 activates endogenous STAT1 and STAT2 in vivo. SgkS78D, sgkS78A and sgkK127M were transfected to PC12 cells and STAT1 phosphorylation at Tyr-701, Ser-727 and STAT2 phosphorylation at Tyr-690 was examined by western blot using specific phospho-(p) antibodies. Results revealed that $s g k S 78 D$ apparently increased the level of STAT1 phosphorylation at Tyr-701 and Ser-727, but this effect was reversed by both $s g k S 78 A$ and $s g k K 127 M$ transfection (Figure $3 \mathrm{~g}$ ). The effectiveness of $s g k S 78 D, s g k S 78 A$ and $s g k K 127 M$ 
a

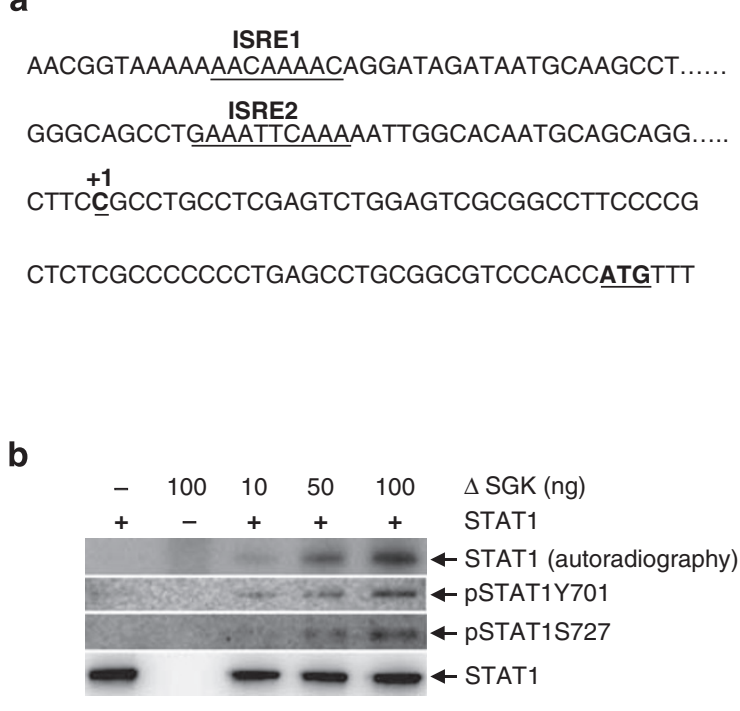

e

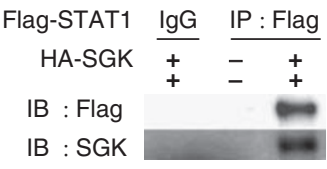

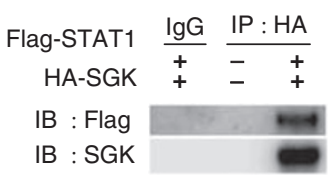

f
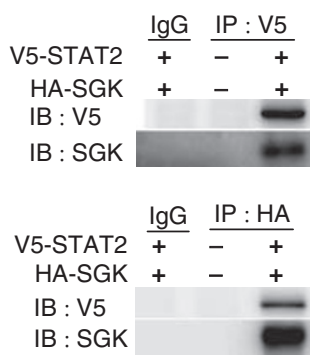

C

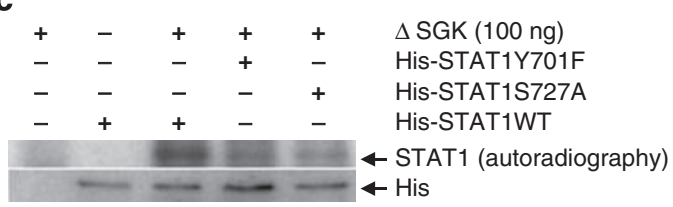

d

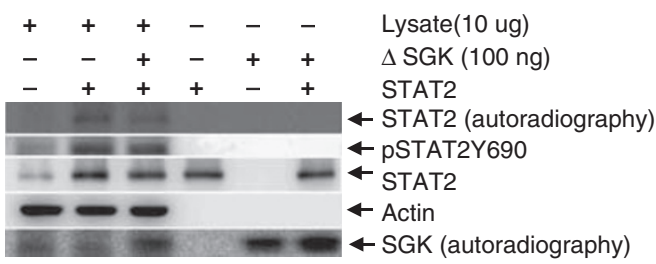

g + - - $\quad-\quad \operatorname{pcDNA3}(3.2 \mu \mathrm{g})$

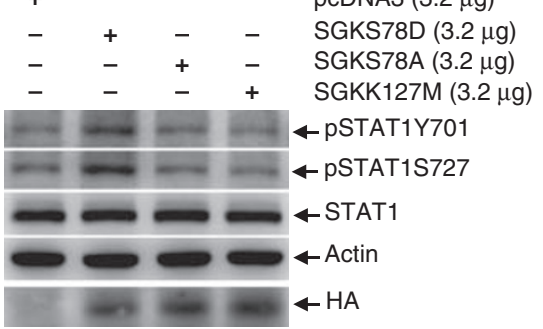

$\mathbf{h}$

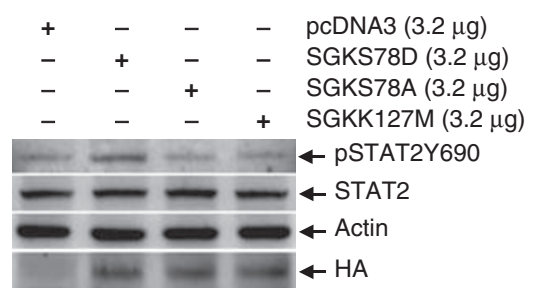

Figure 3 SGK1 directly phosphorylates STAT1 and indirectly activates STAT2. (a) The promoter region of the Mcl-1 gene contains two ISRE elements (sequence is underlined) specific for STAT1/STAT2 binding. (b) Various concentrations of active sgk1 and recombinant STAT1 protein were incubated for in vitro kinase assay and western blot. (c) Active SGK1 (100 ng) and His-tagged STAT1 WT and STAT1 mutant proteins were incubated for in vitro kinase assay and western blot. (d) Active SGK1 (100 ng), recombinant STAT2 protein and PC12 cell lysate were incubated for in vitro and in vivo kinase assay and western blotting. (e) HA-SGK1 (1.6 $\mu \mathrm{g})$ and Flag-STAT1 (1.6 $\mu \mathrm{g})$ plasmids were co-transfected to HEK293T cells for immunoprecipitation (IP) and immunoblotting (IB). (f) HA-SGK1 (1.6 $\mu \mathrm{g})$ and V5-STAT2 (1.6 $\mu \mathrm{g})$ plasmids were cotransfected to HEK293T cells for IP and IB assays. SgkS78D, sgkS78A and sgkK127M were transfected to PC12 cells for analyzing (g) STAT1 phosphorylation and (h) STAT2 phosphorylation by western blot $48 \mathrm{~h}$ later. Transfection and expression of these sgk1 plasmids was confirmed by western blot against HA. Data are expressed as mean \pm S.E.M. Experiments are in duplicates

transfection and expression was confirmed by western blot against HA (Figure $3 \mathrm{~g}$, bottom). Meanwhile, sgkS78D increased STAT2 phosphorylation at Tyr-690, and this effect was also reversed by $s g k S 78 A$ and $s g k K 127 M$ transfection (Figure 3h). Sgk1 plasmid transfection and expression was confirmed by western blot against HA (Figure 3h, bottom). These results showed that SGK1 directly phosphorylates STAT1 and indirectly activates STAT2.

A $\beta$ activates STAT1 and STAT2 through activation of SGK1 at Ser-78. The above results showed that $A \beta$ activates SGK1 at Ser-78, and SGK1 phosphorylation at Ser-78 activates STAT1 and STAT2, but these results do not reveal whether $\mathrm{A} \beta$ could also activate STAT1 and STAT2 and whether A $\beta$ activation of STAT1 and STAT2 is mediated through SGK1 Ser-78 activation. Time course study of $A \beta$ treatment on STAT1 and STAT2 phosphorylation was carried out by western blot using specific p-antibodies. A representative gel pattern is shown in Figure 4a. Results revealed that $\mathrm{A} \beta$ increased STAT1 phosphorylation at Tyr-701 (Figure 4b, upper) and Ser-727 (Figure 4b, lower) 15,30 and 60 min later $(P<0.05$ or $P<0.01)$, but transfection 
a
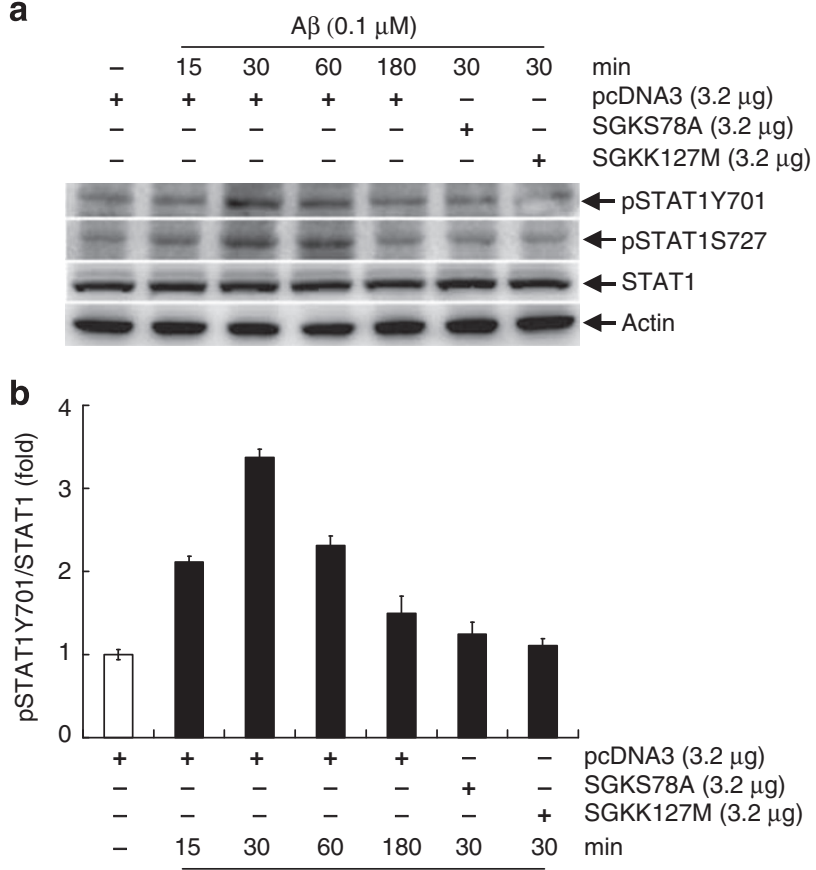

$\mathrm{A} \beta(0.1 \mu \mathrm{M})$

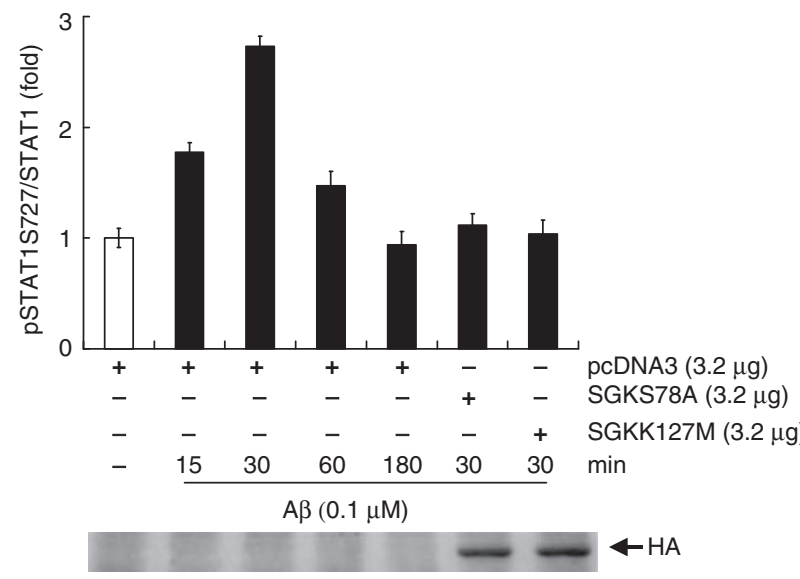

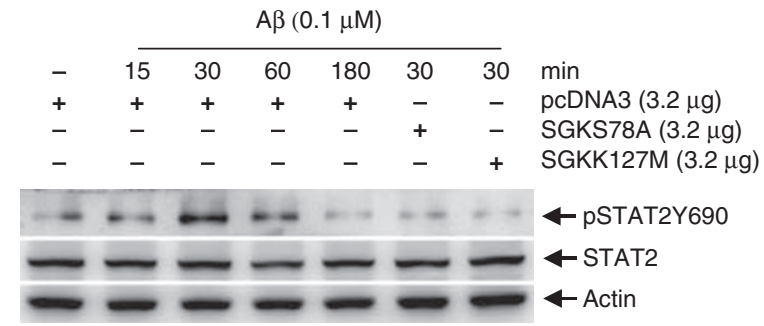

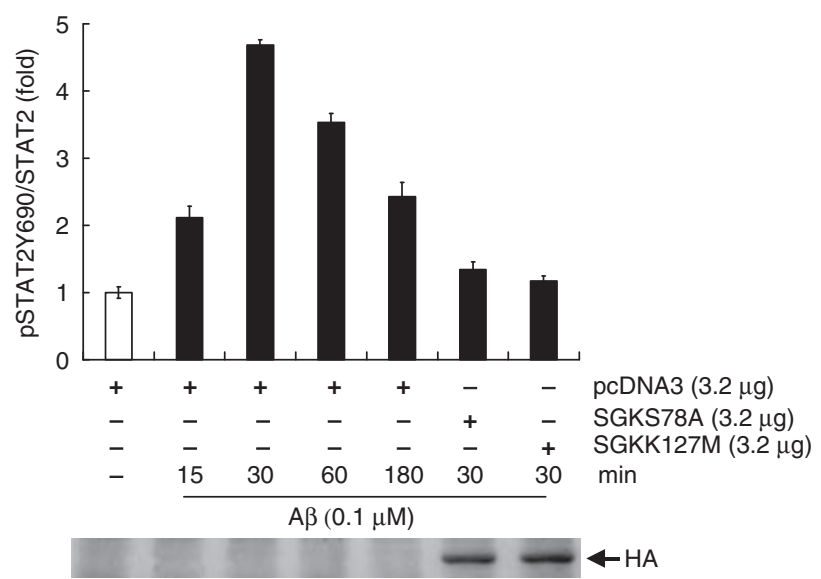

d
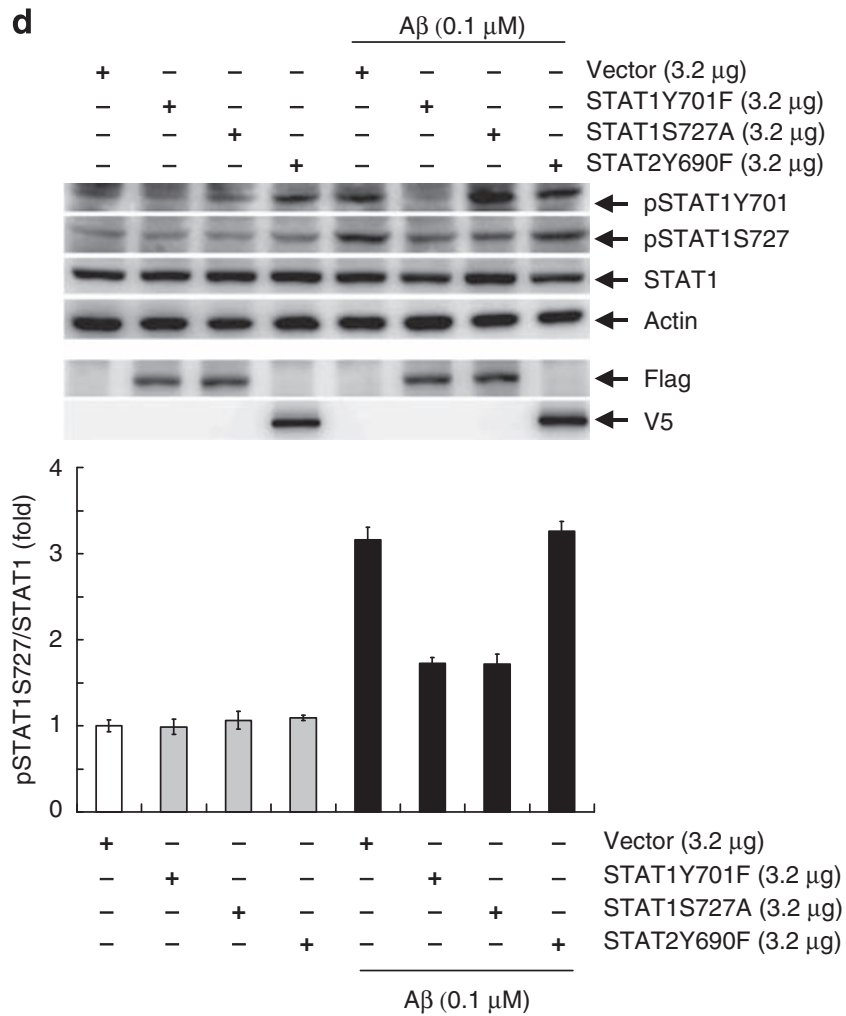

Figure $4 \mathrm{~A} \beta$ activation of STAT1 and STAT2 is mediated through SGK Ser-78 activation. A $\beta$ was added to PC12 cells with or without $s g k S 78 A$ and $s g k K 127 M$ transfection ( $24 \mathrm{~h}$ before $\mathrm{A} \beta$ ) and (a, b) STAT1 phosphorylation (c) STAT2 phosphorylation was assessed at various time points after A $\beta$ by western blot and quantified. Transfection and expression of sgkS78A and sgkK127M was confirmed by western blot against HA. (d) The stat1 or stat2 mutant plasmid was transfected to PC12 cells $24 \mathrm{~h}$ before A $\beta$ for assessment of STAT1 and STAT2 phosphorylation by western blot 30 min after A $\beta$. Transfection and expression of the stat1 mutant and stat2 mutant was confirmed by western blot against the Flag tag and V5 tag, respectively (upper). The result of STAT1 Ser-727 phosphorylation level was also quantified (lower). Data are expressed as mean \pm S.E.M. Experiments are in triplicates 
of $s g k S 78 A$ and $s g k K 127 M$ both antagonized this effect of $A \beta$ ( $P<0.01$ compared with $\mathrm{A} \beta$ group at $30 \mathrm{~min})$. Transfection and expression of $s g k S 78 A$ and $s g k K 127 M$ was confirmed by western blot against HA (Figure $4 \mathrm{~b}$, bottom). Similar results were found with STAT2. A $\beta$ increased STAT2 phosphorylation at Tyr-690 15, 30, 60 and $180 \mathrm{~min}$ later $(P<0.05$ or $P<0.01)$, but this effect was also antagonized by sgkS78A and sgkK127M transfection $(P<0.01$ compared with $\mathrm{A} \beta$ group at $30 \mathrm{~min}$ ) (Figure 4c). $S g k S 78 A$ and sgkK127M transfection and expression was confirmed by western blot against HA (Figure 4c, bottom).

Next, we examined whether $\mathrm{A} \beta$ activation of STAT1 at Tyr-701 is dependent on a prior activation of STAT1 at Ser727 or vice versa. The STAT1 mutant plasmids were transfected to $\mathrm{PC} 12$ cells $24 \mathrm{~h}$ before $\mathrm{A} \beta$. Results revealed that $\mathrm{A} \beta$ increased endogenous STAT1 phosphorylation a

Table I. Sequence of GAS, ISRE and STAT3 luciferase construct in the TA-luc vector

\begin{tabular}{ll}
\hline Element & \multicolumn{1}{c}{ Sequence } \\
\hline GAS & AGGTTTCCGGGAAAGCAG \\
ISRE & GAAACTGAAAC \\
STAT3 & TGCTTCCCGGAACGT \\
\hline
\end{tabular}
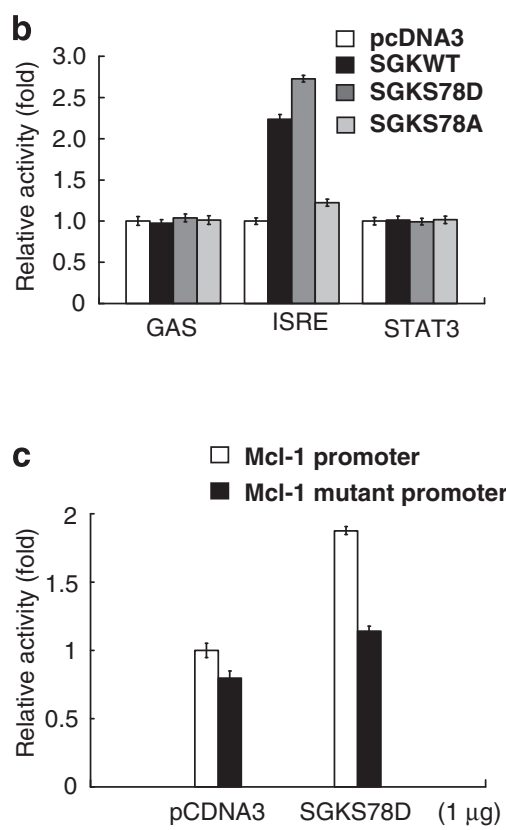
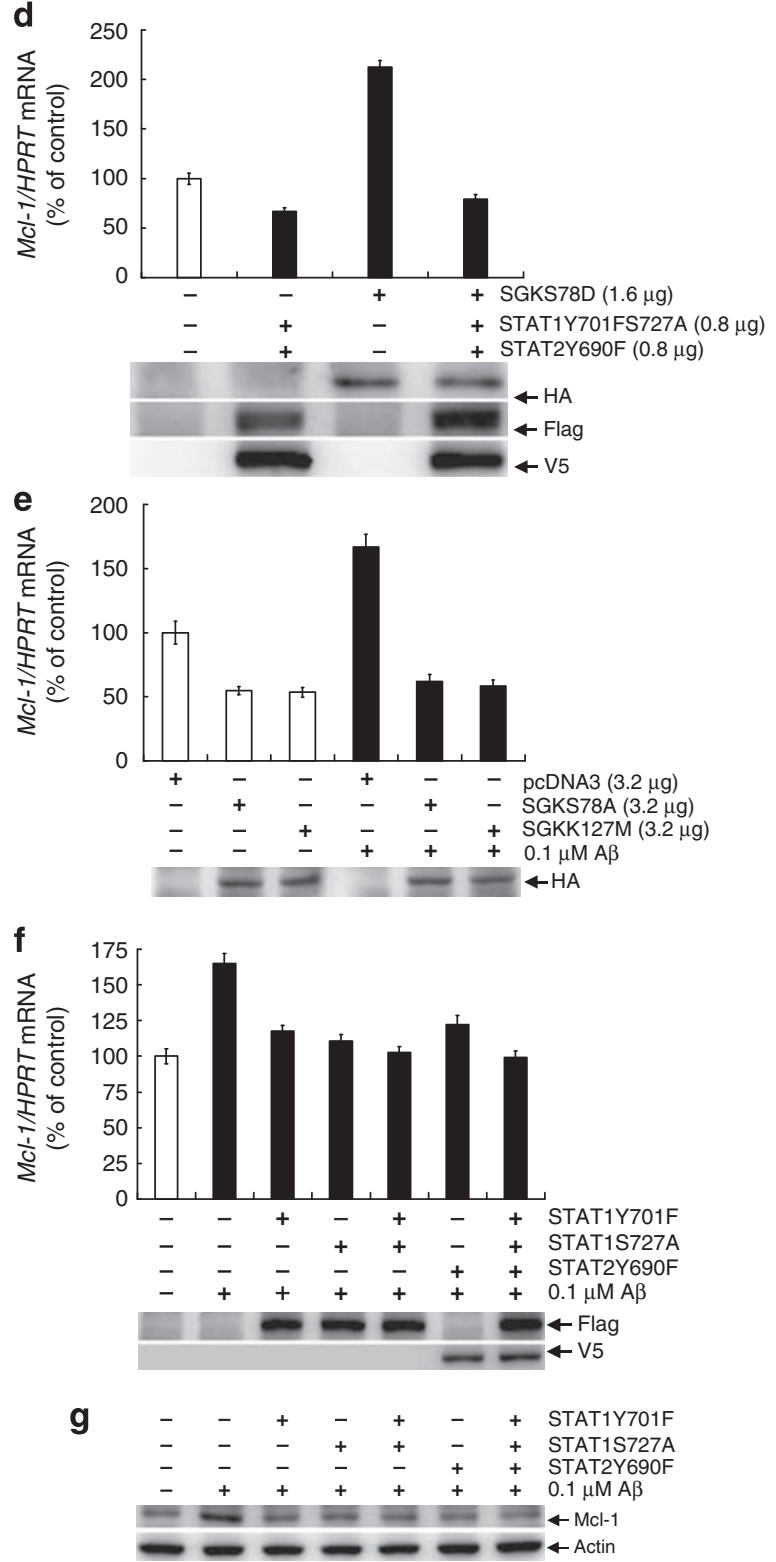

Figure 5 SGK1 increases the promoter activity and gene expression of Mcl-1 through STAT1/STAT2. (a) Sequences of GAS, ISRE and STAT3 for TA-Luc vector are shown. (b) Different sgk1 plasmids (1.0 $\mu \mathrm{g}$ each) and different STAT promoters ( $0.55 \mu \mathrm{g}$ each) were co-transfected to PC12 cells for luciferase assay $24 \mathrm{~h}$ later. (c) SgkS78D and $\mathrm{MCl}-1$ promoter or $\mathrm{Mcl}-1$ mutant promoter ( $0.55 \mu \mathrm{g}$ each) were co-transfected to PC12 cells for luciferase assay $24 \mathrm{~h}$ later. (d) SgkS78D and STAT1 double mutant plasmid or STAT2 mutant plasmid were co-transfected to PC12 cells for Mcl-1 mRNA determination assessed by real-time PCR $48 \mathrm{~h}$ later. Transfection and expression of the sgk plasmid, stat 1 mutant plasmid and stat2 mutant plasmid was confirmed by western blot against the HA tag, Flag tag and V 5 tag, respectively. (e) $S g k S 78 A$ and $s g k K 127 M$ was transfected to PC12 cells, with ( $24 \mathrm{~h}$ before) or without $\mathrm{A} \beta$, for Mcl- $1 \mathrm{mRNA}$ determination assessed by real-time PCR $24 \mathrm{~h}$ after $\mathrm{A} \beta$ treatment. Transfection and expression of sgkS78A and sgkK127M was confirmed by western blot against HA. (f) The stat1 and stat2 mutant plasmids (1.6 $\mu \mathrm{g}$ each for stat1 or stat2 mutant alone or $0.8 \mu \mathrm{g}$ each for both stat1 mutant co-transfection), with ( $24 \mathrm{~h}$ before) or without A $\beta$, were transfected to PC12 cells for Mcl-1 mRNA determination assessed by real-time PCR, or for (g) Mcl-1 protein determination assessed by western blot $24 \mathrm{~h}$ after $\mathrm{A} \beta$. Transfection and expression of the stat 1 mutant and stat2 mutant was confirmed by western blot against Flag and V5, respectively. Data are expressed as mean \pm S.E.M. Experiments are in triplicates 
at both Tyr-701 and Ser-727, but prior transfection of stat1Y701F abolished the effect of A $\beta$ on STAT1 phosphorylation at Ser-727 $(P<0.01$, comparing the pSTAT1S727 band in lane 5 and lane 6 of Figure $4 d$, upper panel). The quantification result is shown in the lower panel of Figure $4 \mathrm{~d}$.
However, transfection of stat1S727A did not affect $\mathrm{A} \beta$ activation of STAT1 at Tyr-701. The stat1 and stat2 plasmid transfection and expression was confirmed by western blot against the Flag tag and V5 tag, respectively (Figure 4d, upper).
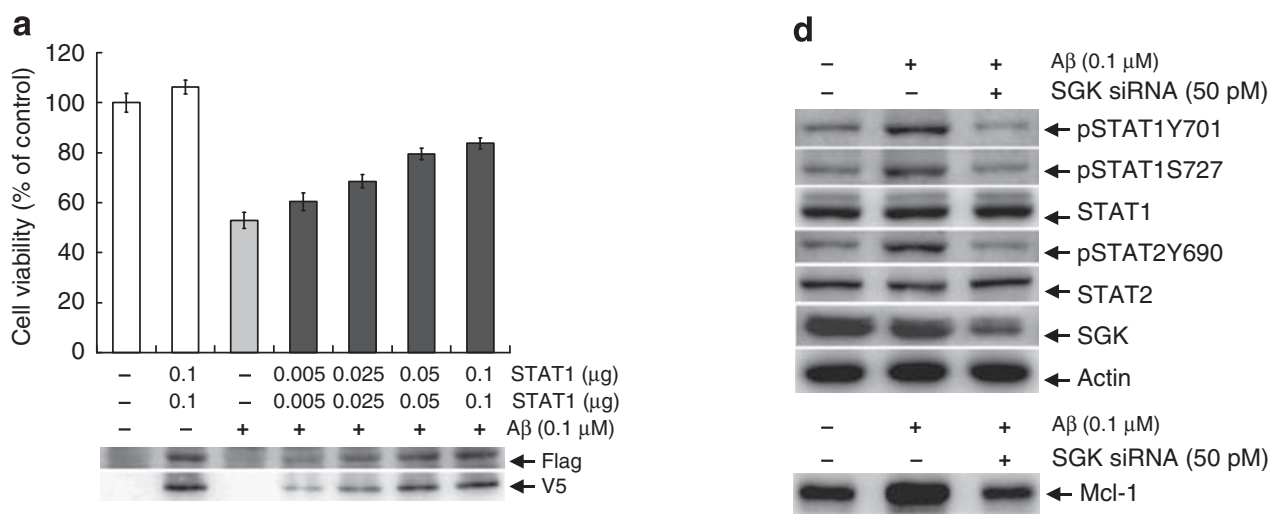

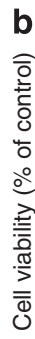

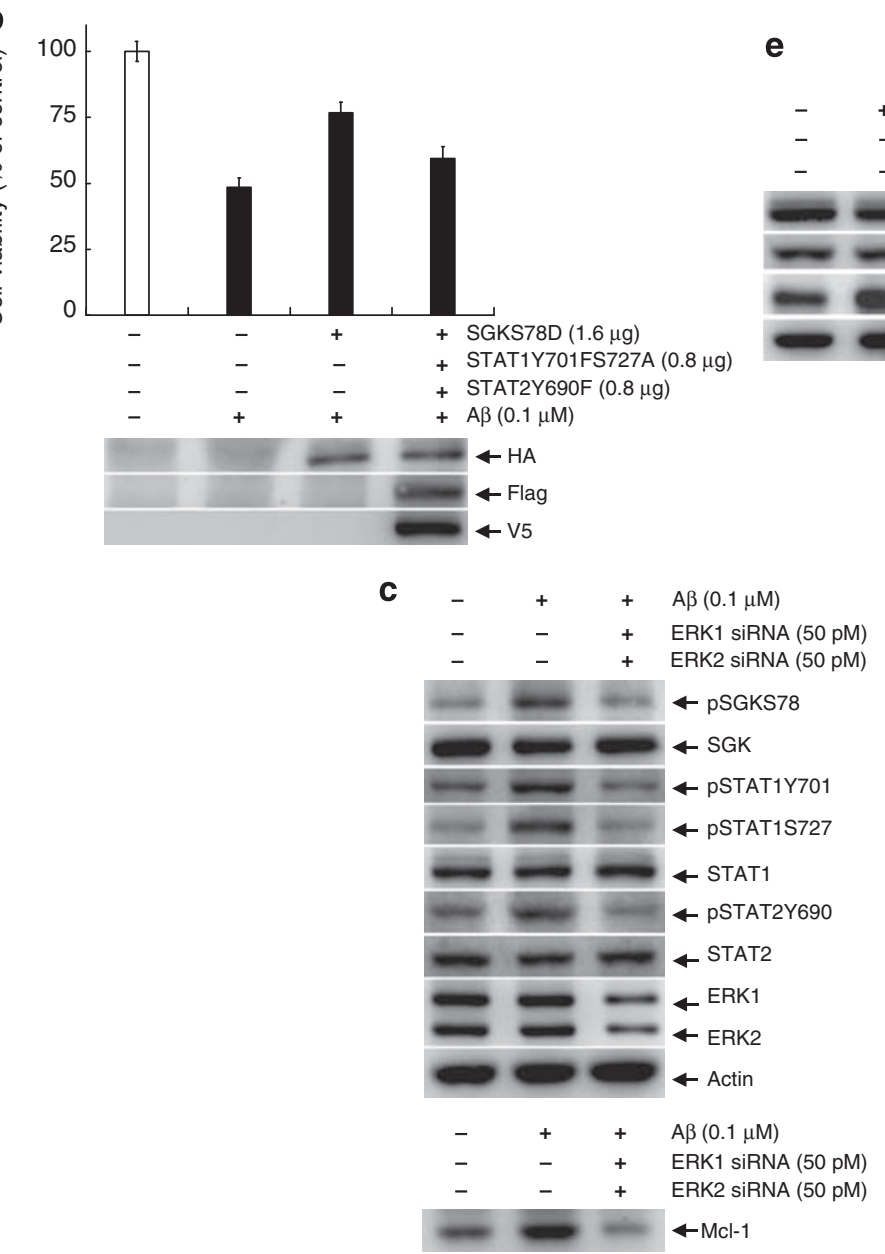

Figure 6 SGK1 protects against A $\beta$-induced apoptosis through STAT1/STAT2. (a) The stat1 and stat2 plasmids alone or various concentrations of the stat1, stat2 wildtype plasmids were co-transfected to PC12 cells $24 \mathrm{~h}$ before A $\beta$ for cell viability determination done by MTT assay $24 \mathrm{~h}$ after A $\beta$. (b) SgkS78D, alone or in combination with the stat 1 and stat2 mutants, were transfected to $\mathrm{PC} 12$ cells $24 \mathrm{~h}$ before $\mathrm{A} \beta$ for cell viability determination done by MTT assay $24 \mathrm{~h}$ after $\mathrm{A} \beta$. Transfection and expression of the sgk plasmid, stat1 plasmid and stat2 plasmid was confirmed by western blot against HA, Flag and V5, respectively. (c) ERK1 siRNA and ERK2 siRNA was transfected to PC12 cells $48 \mathrm{~h}$ before $A \beta$, and the phosphorylation level of ERK $1 / 2$, SGK1 and STAT1/STAT2 was measured 30 min after A $\beta$ by western blot. Mcl-1 expression was measured $24 \mathrm{~h}$ after A $\beta$. (d) SGK1 siRNA was transfected to PC12 cells $48 \mathrm{~h}$ before A $\beta$ and phosphorylation of SGK1 and STAT1/STAT2 was measured 30 min after A $\beta$. Mcl-1 expression was measured $24 \mathrm{~h}$ after A $\beta$. (e) STAT1 siRNA and STAT2 siRNA was transfected to PC12 cells $48 \mathrm{~h}$ before A $\beta$ and STAT1, STAT2, Mcl-1 protein level was measured $24 \mathrm{~h}$ after $\mathrm{A} \beta$ by western blot. Data are expressed as mean \pm S.E.M. Experiments are in triplicates 
At this point, we have adopted the reverse $A \beta$ as a control to examine whether $A \beta_{42-1}$ might also affect ERK $1 / 2$ phosphorylation, SGK1 phosphorylation, STAT1/STAT2 phosphorylation and $\mathrm{Mcl}-1$ expression as that observed with $\mathrm{A} \beta_{1-42}$. Results showed that the same concentration of $\mathrm{A} \beta_{42-1}(0.1 \mu \mathrm{M})$ added to PC12 cells did not affect any of these measures (Supplementary Figure S3).

SGK1 increases $\mathrm{Mcl}-1$ promoter activity and gene expression through the mediation of STAT1/ STAT2. The above results showed that $\mathrm{A} \beta$ activates STAT1/STAT2 through SGK1 Ser-78 phosphorylation, and SGK1 Ser-78 activation increases Mcl-1 expression. Although the $\mathrm{Mcl}-1$ promoter contains the STAT1/STAT2 binding site (ISRE), it is not known whether SGK1 upregulates $\mathrm{Mcl}-1$ expression through the mediation of STAT1/STAT2 and whether A $\beta$ increases $\mathrm{Mcl}-1$ expression through the mediation of SGK1 Ser-78 activation. The present experiment examined this issue. Different STAT dimer-binding elements were constructed into TA Luc-vector, including ISRE (for STAT1/STAT2), STAT3 (for STAT3/ STAT3) and GAS (for STAT1/STAT1 and STAT1/STAT3) (Figure $5 \mathrm{a}$ ). These constructs were transfected to PC12 cells together with $s g k W T, s g k S 78 D$ or $s g k S 78 A$ and luciferase assay was performed $24 \mathrm{~h}$ later. Results revealed that both $s g k W T$ and $s g k S 78 D$ increased ISRE luciferase activity without affecting the luciferase activity of STAT3 and GAS $(P<0.01)$ (Figure 5b). Next, we examined whether SGK1 increases $\mathrm{Mcl}-1$ expression through the mediation of ISRE. Two nucleotides of two ISRE elements on the $\mathrm{Mcl}-1$ promoter were mutated separately (AA mutated to GT from nucleotide -402 to -403 and AAA mutated to GAC from nucleotide -308 to -310 ) and this construct was co-transfected with $s g k S 78 D$ to $\mathrm{PC} 12$ cells. Results revealed that $s g k S 78 D$ increased the luciferase activity of $\mathrm{Mcl}-1$ wild-type promoter $(P<0.01)$, but not $\mathrm{Mcl}-1$ mutant promoter (Figure $5 \mathrm{c}$ ).

As $s g k S 78 D$ increased ISRE promoter activity and Mcl-1 expression (Figure 2f), we next examined whether $s g k S 78 D$ upregulates $\mathrm{Mcl}-1$ expression through the mediation of STAT1/STAT2. SgkS78D and the STAT1, STAT2 mutant plasmids (stat1 Y701F/stat1S727A and stat2Y690F) were cotransfected to PC12 cells and Mcl-1 mRNA expression was examined. Results revealed that $s g k S 78 D$ increased $M c l-1$ mRNA level $(P<0.01)$, but this effect was completely reversed by co-transfection of the STAT1 and STAT2 mutant plasmids $(P<0.01$ compared with sgkS78D group) (Figure $5 d$ ). Transfection and expression of these plasmids was confirmed by western blot against HA, Flag and V5, respectively (Figure $5 d$, bottom).

Next, we examined whether $\mathrm{A} \beta$ increases $\mathrm{Mcl}-1$ expression through the mediation of SGK1 Ser-78 activation. SgkS78A and $s g k K 127 M$ were transfected to $\mathrm{PC} 12$ cells $24 \mathrm{~h}$ before $\mathrm{A} \beta$. Results revealed that $\mathrm{A} \beta$ markedly increased $\mathrm{Mcl}-1 \mathrm{mRNA}$ level $(P<0.01)$, but this effect was completely antagonized by prior sgkS78A and sgkK127M transfection (both $P<0.01$ compared with $\mathrm{A} \beta$ group) (Figure $5 \mathrm{e}$ ). Transfection and expression of $s g k S 78 A$ and $s g k K 127 M$ was confirmed by western blot against HA (Figure $5 \mathrm{e}$, bottom).

Lastly, we examined whether $\mathrm{A} \beta$ upregulates $\mathrm{Mcl}-1 \mathrm{mRNA}$ expression and protein expression through the mediation of
STAT1/STAT2. Stat1Y701F, stat1S727A and stat2Y690F mutant plasmid, alone or in combination, was transfected to PC12 cells together with $\mathrm{A} \beta$. Results revealed that $\mathrm{A} \beta$ increased $\mathrm{Mcl}-1$ mRNA level $(P<0.01)$, but transfection of any of the STAT mutant plasmid blocked this effect of $\mathrm{A} \beta$ $(P<0.01$ compared with $A \beta$ group, Figure $5 \mathrm{f})$. Transfection and expression of the STAT1 and STAT2 mutant plasmids was confirmed by western blot against Flag and V5, respectively (Figure $5 \mathrm{f}$, bottom). Meanwhile, transfection of these mutant plasmids also blocked $\mathrm{A} \beta$-induced $\mathrm{Mcl}-1$ protein expression (Figure $5 \mathrm{~g}$ ).

SGK1 protects against $A \beta$-induced apoptosis through the mediation of STAT1/STAT2. The above results showed that SGKS78D protects against $A \beta$-induced apoptosis and that SGK1 signals to STAT1/STAT2, but it is not known whether the protective effect of SGKS78D is mediated through STAT1/STAT2. This issue was examined here. Different concentrations of STAT1/STAT2 wild-type plasmid were transfected to PC12 cells together with $\mathrm{A} \beta$ for cell viability assay. Results revealed that $\mathrm{A} \beta$ markedly decreased cell viability $(P<0.01)$, but this effect was reversed by stat1/stat2 transfection in a dose-dependent manner $(P<0.05$ or $P<0.01)$ (Figure 6a). Transfection of stat1/stat2 alone was without a marked effect. Transfection and expression of the stat1 and stat2 plasmids was confirmed by western blot against Flag and V5, respectively (Figure 6a, bottom). Next, the stat1Y701F/ stat1S727A/stat2Y690F mutant plasmid was co-transfected with sgkS78D together with $A \beta$ for cell viability assay. Results revealed that $\mathrm{A} \beta$ decreased cell viability $(P<0.01)$. Transfection of $s g k S 78 D$ effectively protects against this effect of $\mathrm{A} \beta \quad(P<0.01$ compared with $\mathrm{A} \beta$ group), but this protective effect was further reversed by stat1Y701F/ stat1S727A/stat2Y690F co-transfection $(P<0.01$ compared with $s g k S 78 D+\mathrm{A} \beta$ group) (Figure $6 \mathrm{~b}$ ). Transfection and expression of the $s g k 1$, stat 1 and stat2 mutant plasmid was confirmed by western blot against HA, Flag and V5, respectively (Figure $6 b$, bottom).

To further confirm that $\mathrm{A} \beta$ treatment and stat1, stat2 transfection does affect cell death rather than cell proliferation in the above experiments, additional experiment with TUNEL assay was carried out. Result showed that $A \beta$ consistently induced apoptotic cell death, but this effect is partially inhibited by stat $1 /$ stat2 transfection ( $0.1 \mu \mathrm{g}$ each) (Supplementary Figure S4). As the same issue for $s g k S 78 D$ transfection has been examined earlier (Supplementary Figure S2), it is not studied again here regarding the results obtained from Figure $6 \mathrm{~b}$.

Verification of ERK1/2-, SGK1- and STAT1/STAT2mediated signaling and $\mathrm{Mcl}-1$ expression on $\mathrm{A} \beta$ insult by using siRNA knockdowns. The above results together showed a novel endogenous signaling pathway that is activated on $\mathrm{A} \beta$ insult to mediate cell survival. However, some of these experiments have used the overexpression strategy. To further confirm the role of these molecules involved in this signaling pathway and biological response, specific siRNA against each molecule is used here. In the first experiment, ERK1 siRNA and ERK2 siRNA $(50 \mathrm{pmol}$ each) was first transfected to PC12 cells. A $\beta$ was given $48 \mathrm{~h}$ 
after these siRNA transfections and SGK1 phosphorylation, STAT1/STAT2 phosphorylation was examined $30 \mathrm{~min}$ after $\mathrm{A} \beta$ treatment. Alternatively, Mcl-1 expression was examined $24 \mathrm{~h}$ after $\mathrm{A} \beta$. Results in Figure $6 \mathrm{c}$ revealed that $\mathrm{A} \beta$ consistently increased SGK1 phosphorylation at Ser-78, STAT1 phosphorylation at Tyr-701 and Ser-727, STAT2 phosphorylation at Tyr-690 and Mcl-1 protein expression. All these effects were blocked by prior ERK1 siRNA and ERK2 siRNA transfection. The effectiveness of ERK1 siRNA and ERK2 siRNA transfection was confirmed by an obvious reduction in ERK1 and ERK2 protein level, respectively.

Next, to show that STAT1/STAT2 phosphorylation and Mcl1 expression induced by $A \beta$ is mediated through SGK1, SGK1 siRNA ( 50 pmol) was transfected to PC12 cells $48 \mathrm{~h}$ before $\mathrm{A} \beta$ treatment. STAT1/STAT2 phosphorylation was measured 30 min after $\mathrm{A} \beta$, whereas $\mathrm{Mcl}-1$ expression was measured $24 \mathrm{~h}$ after $\mathrm{A} \beta$. Results revealed that $\mathrm{A} \beta$ increased STAT1 phosphorylation at Tyr-701 and Ser-727, STAT2 phosphorylation at Tyr-690 and Mcl-1 protein expression. But these effects were completely abolished by prior SGK1 siRNA transfection (Figure 6d). The effectiveness of SGK1 siRNA transfection was confirmed by an apparent reduction of SGK1 protein level (Figure 6d).

Lastly, we need to verify that $A \beta$-induced increase in Mcl-1 protein expression is mediated through STAT1 and STAT2. To address this issue, STAT1 siRNA and STAT2 siRNA (50 pmol each) was transfected to $\mathrm{PC} 12$ cells $48 \mathrm{~h}$ before $\mathrm{A} \beta$ treatment and Mcl-1 expression was measured $24 \mathrm{~h}$ after $\mathrm{A} \beta$. Results revealed that prior STAT1 siRNA and STAT2 siRNA transfection completely antagonized $\mathrm{A} \beta$-induced $\mathrm{Mcl}-1$ protein expression (Figure 6e). The effectiveness of STAT1 siRNA and STAT2 siRNA transfection was confirmed by a marked reduction in STAT1 and STAT2 protein level, respectively.

\section{A $\beta$ activates SGK1 signaling for cell protection in rat} hippocampus. The above results together showed a novel ERK1/2-SGK1-STAT1/STAT2 signaling pathway that is activated on $\mathrm{A} \beta$ insult to mediate cell protection in $\mathrm{PC} 12$ cells. This study examined this issue in rat hippocampus. $\mathrm{A} \beta$ $(24 \mu \mathrm{g})$ and reverse $\mathrm{A} \beta\left(\mathrm{A} \beta_{42-1}\right)(24 \mu \mathrm{g})$ were directly injected into hippocampal CA1 area in different animals and ERK1/2 phosphorylation, SGK1 phosphorylation, STAT1/STAT2 phosphorylation and $\mathrm{Mcl}-1$ expression were measured at various time points after these treatments. Consistent with that observed in $\mathrm{PC} 12$ cells, results showed that $\mathrm{A} \beta$ injection apparently increased the phosphorylation level of ERK1/2, SGK1 at Ser-78, STAT1 at Tyr-701 and Ser-727, STAT2 at Tyr-690 $30 \mathrm{~min}$ later. This effect gradually declined thereafter. Meanwhile, $\mathrm{A} \beta$ also increased $\mathrm{Mcl}-1$ expression $24 \mathrm{~h}$ later (Figure 7a). However, the same concentration of a

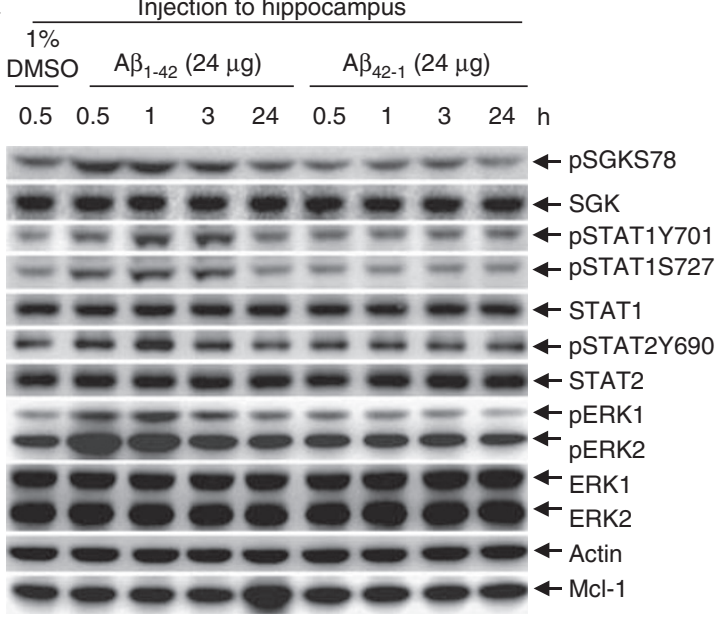

C

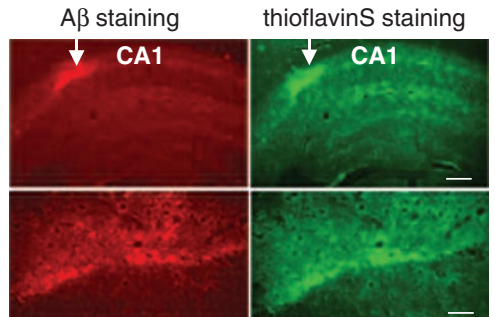

b
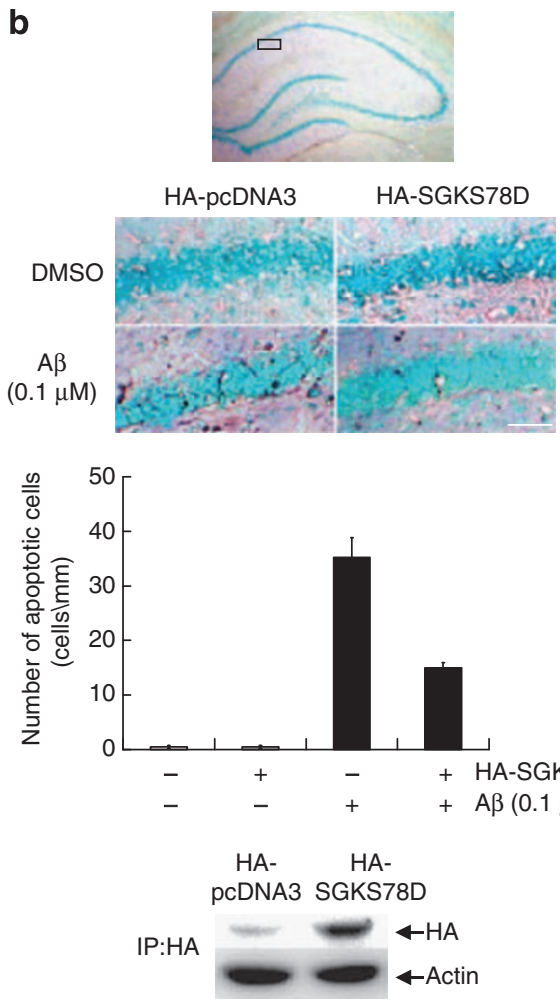

Figure $7 \quad A \beta$ activates SGK1 signaling for cell protection in rat hippocampus. (a) $A \beta$ and reverse $A \beta$ were directly injected into hippocampal CA1 area bilaterally in different rats and the phosphorylation level of ERK1/2, SGK1, STAT1 and STAT2 in CA1 area was measured at different time points after these injections by western blot. The total ERK1/2, SGK1, STAT1, STAT2 and Mcl-1 protein level was also examined. (b) Apoptotic nucleus in CA1 area was evaluated by TUNEL staining (brown color) and quantified 7 days after $A \beta$ injection with or without $s g k S 78 D(1.6 \mu \mathrm{g})$ transfection. Transfection and expression of $s g k S 78 D$ was confirmed by immunoprecipitation and western blot against HA. The upper panels are magnifications of the area indicated in the top figure. Scale bar $=100 \mu \mathrm{m}$. Data are expressed as mean \pm S.E.M. (c) Immunohistochemistry staining showing the position of $\mathrm{A} \beta$ injection in $\mathrm{CA} 1$ area (red) and the position of $\mathrm{A} \beta$ aggregate formation (thioflavin $\mathrm{S}$ staining, green) in $\mathrm{CA} 1$ area. $\mathrm{Scale}$ bar $=350 \mu \mathrm{m}$ for upper panels and scale bar $=100 \mu \mathrm{m}$ for lower panels. Arrows indicate where $\mathrm{A} \beta$ was injected. Experiments are in triplicates 
reverse $\mathrm{A} \beta$ did not produce any of these effects at any time point examined (Figure 7a).

To examine whether $\mathrm{A} \beta$ does produce toxicity in hippocampal neurons, and whether $s g k S 78 D$ protects against $\mathrm{A} \beta$-induced toxicity, we also examined $\mathrm{A} \beta$-induced apoptosis and neuronal loss in rat hippocampus. Results from TUNEL staining showed that $\mathrm{A} \beta$ injection to hippocampal $\mathrm{CA} 1$ area markedly increased the number of apoptotic cells $(P<0.01)$, $s g k S 78 D$ transfection partially, but significantly, inhibited $\mathrm{A} \beta$-induced cell death $(P<0.05$ compared with $\mathrm{A} \beta$ group) (Figure $7 \mathrm{~b}$ ). Transfection and expression of $s g k S 78 D$ in CA1 neurons was confirmed by immunoprecipitation and western blot against the HA tag (Figure $7 \mathrm{~b}$, bottom). The same $\mathrm{A} \beta$ injection also apparently decreased the number of NeuNpositive cells in the hippocampus (Supplementary Figure S5), confirming the toxicity of $\mathrm{A} \beta$ produced in neurons. Figure $7 \mathrm{c}$ is the immunohistochemical staining for $\mathrm{A} \beta$ (red) and thioflavin $\mathrm{S}$ (green) showing that $\mathrm{A} \beta$ was indeed injected into the hippocampal CA1 area and the injected $\mathrm{A} \beta$ does form aggregates, respectively.

\section{Discussion}

The present results show a novel SGK1-STAT1/STAT2 pathway that is activated on $\mathrm{A} \beta$ insult to upregulate $\mathrm{Mcl}-1$ expression to mediate cell survival. $\mathrm{A} \beta$ was shown to activate SGK1 at Ser-78 selectively to activate this pathway. This result is consistent with the finding that p38 MAPK activation of SGK1 at Ser-78 also mediates cell survival. ${ }^{11}$ In examination of the possible upstream signal of SGK1, we have found that $A \beta$ dramatically increased ERK $1 / 2$ phosphorylation at a parallel time course and that ERK1 siRNA and ERK2 siRNA abolished the effect of $A \beta$ on SGK1 Ser-78 activation. This result suggests that $\mathrm{A} \beta$ activation of SGK1 is mediated through ERK1/2. This finding is consistent with the notion that ERK $1 / 2$ plays a survival role against apoptosis ${ }^{31}$ and that ERK1/2 signaling mediates a neuroprotective response. ${ }^{32} \mathrm{~A} \beta$ is a deleterious stimulus that also activates JNK. But our results showed that $A \beta$ activation of SGK1 is independent of $A \beta$ activation of JNK. On the other hand, the same concentration of $\mathrm{A} \beta$ did not increase (it actually decreased) the phosphorylation of Akt1 (Supplementary Figure S6), a protein kinase that shares approximately 55\% sequence homology in its catalytic domain to that of SGK1. ${ }^{10}$ Although PI3$\mathrm{K}$ is also implicated in anti-apoptosis in response to various stress stimuli, our result suggests that it does not mediate $\mathrm{A} \beta$ induced protection mechanism. This result is inconsistent with another report showing that $\mathrm{A} \beta(25-35)$ dramatically increased Akt1 phosphorylation in PC12 cells. ${ }^{33}$ One possible explanation for this discrepancy is probably due to a 400 -fold higher concentration of $A \beta$ used in the latter study. Different signaling pathway and protection mechanism may be activated depending on the extent of $A \beta$ insult. In addition, different $A \beta$ fragments were used in these studies.

In examination of the protective role of SGK1 activation against $\mathrm{A} \beta$-induced apoptosis, we found that transfection of sgkS78D dose-dependently rescued $\mathrm{A} \beta$-induced decrease in cell survival. It also dose-dependently enhanced $\mathrm{Mcl}-1$ expression, and this effect was reversed by sgkS78A. These results are consistent with a recent report showing that SGK1 produces an anti-apoptotic effect through activation of the $\mathrm{I}_{\kappa} \mathrm{B}$ kinase. $^{34}$ It is also congruent with the report that SGK1 promotes cell survival through inactivation of the pro-apoptotic transcriptional factor FKHRL1. ${ }^{12}$ In addition, inactivation of GSK-3 $\beta$ was shown to suppress $A \beta$-induced neurotoxicity ${ }^{35}$ and SGK1 was shown to phosphorylate GSK-3 $\beta$ and reduce its activity. ${ }^{10}$ Therefore, SGK1 may protect against $\mathrm{A} \beta$ toxicity also through inactivation of GSK-3 $\beta$. On the other hand, transfection of the highest concentration of $s g k S 78 D$ did not completely rescue $\mathrm{A} \beta$-induced cell death. This result suggests that other factors are possibly also involved in the protective mechanism against $\mathrm{A} \beta$ toxicity. For example, CK2 was shown to produce an anti-apoptotic and neuroprotective effect ${ }^{36,37}$ and CK2 was also shown to phosphorylate STAT1 to increase heat shock protein and $\mathrm{Mcl}-1$ expression for cell survival. ${ }^{25}$

In studying the downstream molecule that mediates the protective effect of SGK1, we found that SGK1 directly phosphorylates STAT1 at Tyr-701 and Ser-727 and indirectly activates STAT2 at Tyr-690. Further, SGK1 activation of STAT1/STAT2 mediates A $\beta$-induced $\mathrm{Mcl}-1$ expression and rescues $A \beta$-induced apoptosis. STAT1 is implicated in the regulation of apoptosis in many studies, but some studies have suggested an anti-apoptotic role for STAT1. One explanation for this discrepancy is probably due to different dimers formed by STAT1. Our result indicated that the STAT1/STAT2 heterodimer plays an anti-apoptotic role against $\mathrm{A} \beta$ toxicity. Moreover, $\mathrm{A} \beta$ was shown to induce $\mathrm{CREB}$ phosphorylation at Ser-133 through ERK1/2 signaling in PC12 cells. ${ }^{38}$ Our result of identification of this novel SGK1-STAT1/ STAT2 pathway downstream of ERK1/2 signaling is also congruent with the report that p38 MAPK enhances STAT1dependent transcription. ${ }^{39}$ It is well known that STAT1 could be activated by various cytokines and growth factors, but in this study, we are the first to show that STAT1 could also be activated by a neurotoxin to mediate cell survival. Whether STAT1 could also be activated by other neurotoxic stimuli to mediate survival response requires further investigation.

In this study, overexpression of STAT1/STAT2 dosedependently protected against $A \beta$-induced decrease in cell survival, but the highest concentration of STAT1/STAT2 did not completely reverse this effect of $A \beta$. Similar to the situation of $s g k S 78 D$, the involvement of other transcription factors cannot be excluded, such as NF- $\kappa \mathrm{B}$ and CREB. Our results also indicated that SGK1 directly phosphorylates STAT1 but indirectly activates STAT2. Whereas the co-immunoprecipitation experiment revealed that SGK1 is associated with STAT2. The kinase that bridges SGK1 and STAT2 is not known yet, but the Janus kinase (JAK) could be a possible candidate because JAK was shown to phosphorylate the tyrosine residue of STAT2 that provides a docking site for latent STAT1 in response to Type $1 \mathrm{IFN} \alpha / \beta$ stimulation. ${ }^{30}$ In addition, JAK1 contains the RXRXXS/T motif (RCRPVT, amino acid 853-858) that fits to the substrate sequence motif of SGK1 (http:// tw.expasy.org/prosite/). ${ }^{40}$ But the identification of this kinase requires further investigation. Moreover, SGK1 is known as a serine/threonine protein kinase, but we have found that it also phosphorylates the tyrosine residue of STAT1 (Y701). In another study, CK2 (a serine/threonine protein kinase) was found to also phosphorylate the tyrosine residue of Fpr3 (Y184), a nucleolar immunophilin of yeast. ${ }^{41}$ This result suggests that SGK1 could also be a dual specificity kinase in 
the regulation of certain signaling pathway and cellular function. But its dual kinase role requires further examination.

Our results indicated that overexpression of $\mathrm{Mcl}-1$ effectively protected against $\mathrm{A} \beta$-induced apoptosis, whereas $\mathrm{Mcl}-1$ siRNA potentiated $\mathrm{A} \beta$-induced apoptosis. Yet, overexpression of $\mathrm{Mcl}-1$ did not completely block $\mathrm{A} \beta$-induced apoptosis (Figure 1f). It is conceivable that $M c /-1$ is not the only antiapoptotic gene that protects against $\mathrm{A} \beta$ toxicity. For example, our preliminary results revealed that low-to-moderate concentrations of $\mathrm{A} \beta$ also increased the expression of $\mathrm{Bcl} 2$ (Supplementary Figure S7). The signaling pathway that mediates $\mathrm{A} \beta$ activation of $\mathrm{Bc} / 2$ requires further investigation.

In this study, PC12 cells were not treated with nerve growth factor (NGF) and, therefore, the cells remained at a proliferating state. The reason for not adding NGF is because that NGF is well known to activate $\mathrm{ERK} 1 / 2,{ }^{42}$ and we have also found that NGF (50 ng) apparently increased the phosphorylation of ERK1/2, SGK1 at Ser-78 and STAT1 at Tyr-701 and Ser-727 (Supplementary Figure S8). These results would seriously confound the results we obtained with A $\beta$ stimulation. Nevertheless, the present results are verified in the hippocampus in vivo (Figure 7). In addition, this study was designed to use a concentration of $\mathrm{A} \beta(0.1 \mu \mathrm{M})$ that induces approximately $40-50 \%$ apoptosis in PC12 cells because it is our hypothesis that the endogenous survival signaling and response was activated only when there is a low-to-moderate degree of insult (in this case, it is $\mathrm{A} \beta$ ) to counter its apoptotic effect. These results also implicate the biological significance of SGK1 signaling in that a stimulus that activates SGK1 at Ser-78 would protect neurons against $\mathrm{A} \beta$ stimulation and perhaps other environmental insults. It further implicates that induction of $s g k 1$ and stat1/stat2 may play a protective role against neurodegeneration.

In conclusion, here we have shown that low concentration of $\mathrm{A} \beta$ increases the phosphorylation of SGK1 at Ser-78 selectively that is mediated through ERK1/2 activation. SGK1 activation further directly phosphorylates STAT1 at Tyr-701 and Ser-727 and indirectly activates STAT2 at Tyr-690. STAT1/STAT2 phosphorylation consequently upregulates the expression of $\mathrm{Mcl}-1$ which in turn protects against A $\beta$-induced apoptosis (Figure 8). This work shows a novel defense mechanism that is activated on $\mathrm{A} \beta$ insult to add plasticity to the cell for cell survival.

\section{Materials and Methods}

Cell culture. Rat pheochromocytoma (PC12) cells were cultured at a density of $5.4 \times 10^{5}$ cells $/$ well on plates coated with $100 \mu \mathrm{g} / \mathrm{ml}$ poly-L-lysine (Sigma-Aldrich, St. Louis, MO, USA). Cells were maintained in DMEM (Hyclone, Logan, UT, USA) with $5 \%$ fetal bovine serum (Hyclone), 10\% horse serum (Invitrogen, Carlsbad, CA, USA) and 1\% penicillin/streptomycin. Human embryonic kidney 293T (HEK293T) cells were maintained in DMEM medium supplemented with $10 \%$ horse serum and $1 \%$ penicillin/streptomycin. Cells were cultured in an incubation chamber gassed with $5 \% \mathrm{CO}_{2}$ and $95 \%$ air at $37^{\circ} \mathrm{C}$. The synthetic $\beta$-amyloid peptide $\left(\mathrm{A} \beta_{1-42}\right)$ (Sigma-Aldrich) was dissolved in $1 \%$ DMSO and added to PC12 cells to a final concentration of $0.01,0.05,0.1,0.5,1.0$ and $5.0 \mu \mathrm{M}$. As the biological activity of $\mathrm{A} \beta_{1-42}$ depends on whether it forms oligomers, ${ }^{3}$ we have first examined this issue in PC12 cell. Result from western blot using anti- $A \beta$ antibody showed that $\mathrm{A} \beta_{1-42}$ added to $\mathrm{PC} 12$ cell medium is available in its oligomeric form (Supplementary Figure S9), and this result is consistent with that reported in the literature. ${ }^{43}$ This $A \beta$ treatment was therefore used throughout the experiments. The reverse $\mathrm{A} \beta\left(\mathrm{A} \beta_{42-1}\right)$ (Anaspec, San Jose, CA, USA) was used as a

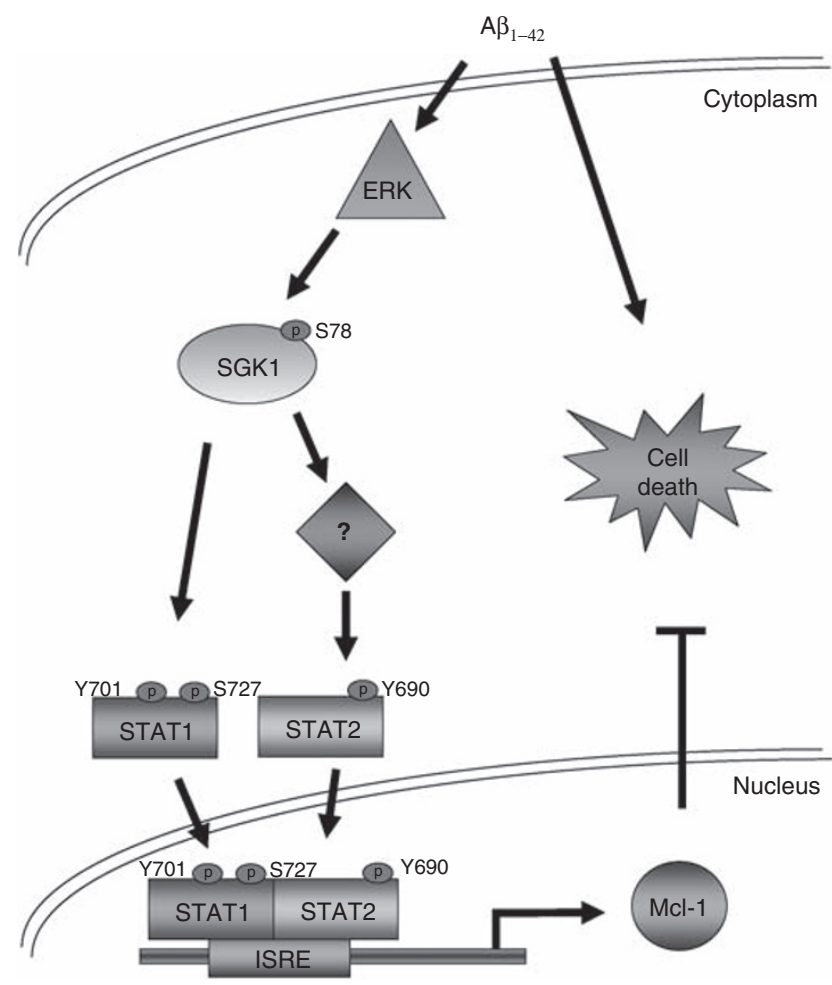

Figure 8 A schematic diagram showing the SGK1-STAT1/STAT2 pathway in the regulation of Mcl- 1 expression that is activated on $A \beta$ insult to rescue cells from apoptotic cell death

negative control..$^{44}$ Cells were incubated for $15,30 \mathrm{~min}, 1,3,6$ or $24 \mathrm{~h}$ at $37^{\circ} \mathrm{C}$ before harvest.

Plasmid DNA construction and transfection. Procedures for construction of pcDNA3-HA-SGK1 (wild-type), sgk1 mutant constructs at Ser-78 (sgkS78A and sgkS78D), Thr-256 (sgkT256A and sgkT256D) and Ser-422 (sgkS422A and sgkS422D) and the kinase-dead sgk1 (sgkK127M) were described elsewhere. $^{9}$ The full-length STAT1-Flag, stat2 and Mcl-1 CDNA plasmids were purchased from Addgene (Cambrige, MA, USA). The STAT2-V5 and Mcl-1-Flag plasmids were constructed by cloning stat2 and $M C l-1 \mathrm{CDNA}$ behind the $\mathrm{V} 5$-His tag of pcDNA3.1/N5-His-TOPO (Invitrogen) and Flag tag of pCMV-Tag 2B (Stratagene, La Jolla, CA, USA), respectively. The mutant stat1 plasmids (stat1Y701F and stat1S727A) and stat2 plasmid (stat2Y690F) were generated by using the QuickChange Site-Directed Mutagenesis Kit (Stratagene). All plasmids were transfected to PC12 cells by using the Lipofectamine 2000 reagent (Invitrogen). The transfection efficiency in PC12 cells is approximately $30-40 \%$ in our system (Supplementary Figure S10), but all the data were obtained from the entire culture rather than from transfected cells only. Thus, there is probably an underestimation of the effects observed with all transfections. But all transfections were successfully confirmed by western blot against the HA, Flag and V 5 tag, respectively.

RNA interference. The following rat siRNAs against each gene were used: ERK1, ERK2, SGK1, STAT1, STAT2, Mcl-1 and the Silencer Negative Control number 1 siRNA. The sense and antisense sequences for each gene is listed in Supplementary Table S1. They were all purchased from Applied Biosystems (Foster City, CA, USA).

MTT assay. PC12 cell viability was evaluated by MTT assay $24 \mathrm{~h}$ after $\mathrm{A} \beta$ treatment or after transfection with various expression plasmids. Cells were incubated with MTT reagent (Sigma-Aldrich) at $37^{\circ} \mathrm{C}$ for $4 \mathrm{~h}$. The amount of MTT formazan product was quantified by measuring its absorbance at 570 and $630 \mathrm{~nm}$ using an ELISA plate reader (Spectra Max 340 PC, Molecular Devices, Sunnyvale, CA, USA). 
TUNEL assay. TUNEL assay by using the Apoptag plus peroxidase in situ apoptosis detection kit was adopted to detect the apoptotic cell according to the manufacturer's protocols (Chemicon, Temecula, CA, USA). TUNEL assay was performed $24 \mathrm{~h}$ after $\mathrm{A} \beta$ treatment or $48 \mathrm{~h}$ after pcDNA3-HA-SGK1, pcDNA3-HASGKS78D, STAT1-Flag, STAT2-V5 and Mcl-1-Flag plasmid transfections in the presence of $\mathrm{A} \beta$. PC12 cells were fixed in $1 \%$ paraformaldehyde and brain sections were fixed in $4 \%$ paraformaldehyde for $10 \mathrm{~min}$. $\mathrm{PC} 12$ cells and brain sections were permeabilized with pre-cold $\mathrm{EtOH} / \mathrm{CH}_{3} \mathrm{COOH}(2: 1)$ for $10 \mathrm{~min}$ at $-20^{\circ} \mathrm{C}$, followed by reacting with $3 \% \mathrm{H}_{2} \mathrm{O}_{2}$ for 5 min to remove the endogenous peroxidase activity. Cells and brain sections were then incubated with the TdT enzyme for $1 \mathrm{~h}$ at $37^{\circ} \mathrm{C}$ followed by incubation with anti-digoxigenin peroxidase conjugate for $30 \mathrm{~min}$. Apoptotic nuclei stained with DAB showed brown color. The slides were then counterstained with methyl green for visualization of total cells. Cells were examined by using a light microscope in three random fields of a given slide and the cell number was counted.

Quantitative real-time PCR. Total RNA from PC12 cells was isolated by using the Ultraspec RNA reagent (Biotecx, Houston, TX, USA). The cDNA was generated from total RNA with Superscript III reverse transcriptase (Invitrogen). Real-time PCR analysis was performed by using the ABI PRISM 7700 sequence detection system with the TaqMan method according to the instruction manual (Applied Biosystems, Foster City, CA, USA). The primers and fluorogenic probes for $\mathrm{Mcl}-1$ and HPRT were purchased from Applied Biosystems. The sgk1 primers and fluorogenic probe were designed by Primer Express Software (Applied Biosystems). The sequences for sgk1 primers and probe were shown in Supplementary Table S2. The relative quantity of $\mathrm{mRNA}$ was estimated by using a standard curve that was created by serial dilution of the reverse transcription product from control samples. Quantitative analysis of $\mathrm{Mcl}-1$ and $s g k 1$ gene expression was normalized to that of HPRT gene expression.

Promoter-luciferase assay. PC12 cells were co-transfected with $0.55 \mu \mathrm{g}$ promoter-firefly luciferase plasmid, $50 \mathrm{ng}$ Renilla luciferase-encoding internal control plasmid phRG-TK, $1 \mu \mathrm{g}$ expression plasmid (or $0.5 \mu \mathrm{g}$ each of the two expression plasmids, respectively) in DMEM medium by Lipofectamine 2000 . Luciferase activity was evaluated by using the Dual-Glo luciferase assay system (Promega) and the TD-20/20 Luminometer (Turner Designs Hydrocarbon Instruments, Fresno, CA, USA). The relative activity was normalized with renilla luciferase activity. Promoterluciferase plasmid Mcl-1-TA-Luc was constructed by cloning the $\mathrm{Mcl}-1$ promoter at nt -45 to $n t-431$ amplified by PCR from rat genomic DNA in front of the firefly luciferase gene of TA-Luc vector (Clontech, Palo Alto, CA, USA). Promoter-fireflyluciferase plasmid GAS-TA-Luc, ISRE-TA-Luc and STAT3-TA-Luc vectors were purchased from Clontech.

Western blot. PC12 cells were lysed in RIPA buffer after plasmid DNA transfection or after $A \beta$ treatment. The lysates were resolved by $8 \%$ SDS-PAGE. The proteins resolved by SDS-PAGE were transferred to the PVDF membrane and western blot was conducted by using the following antibodies: rabbit anti-SGK1, anti-ERK1/2, anti-STAT1, anti-His tag (Upstate, Lake Placid, NY, USA), anti-p-Ser78 SGK1, anti-p-Thr-256 SGK1, anti-p-Ser-422 SGK1, anti-p-ERK1/2, anti-p-Tyr701 STAT1, anti-p-Ser-727 STAT1, anti-p-Tyr-690 STAT2, anti-JNK (Cell Signaling, Danvers, MA, USA), anti-STAT2, anti-Mcl-1 (Santa Cruz Biotechnology, Santa Cruz, CA, USA), anti-p-JNK (Calbiochem, San Diego, CA, USA), anti-HA tag (Roche, Penzberg, Germany), anti-Flag tag(M2) (Sigma-Aldrich), anti-V5 tag (Serotec, Kidlington, UK), and anti-actin (Chemicon) antibodies. The secondary antibodies used include HRP-conjugated goat-anti-rabbit IgG antibody (Chemicon), HRP-conjugated goat-anti-mouse IgG antibody (Upstate) and HRP-conjugated goat-anti-rat IgG antibody (Jackson ImmunoResearch, West Grove, PA, USA). Membrane was developed by reacting with chemiluminescent HRP substrate (Millipore, Bedford, MA, USA) and exposed to X-ray film or LAS-3000 image system (Fujifilm, Tokyo, Japan).

Co-immunoprecipitation. HEK293T cells were co-transfected with equal amount of Tag-fusioned constructs and lysed $48 \mathrm{~h}$ after DNA transfection. The lysates were subjected to immunoprecipitation ( $0.5 \mathrm{mg}$ of total protein) with $10 \mu \mathrm{l}$ mouse anti-Flag M2 affinity gel (Sigma-Aldrich), anti-HA agarose affinity gel (50\% slurry) (Sigma-Aldrich) or anti-V5 agarose affinity gel (50\% slurry) (Sigma-Aldrich) at $4^{\circ} \mathrm{C}$ for $1 \mathrm{~h}$, respectively. After washing with PBS for three times, pellets were eluted by adding $20 \mu \mathrm{l}$ of sample buffer for western blot.
$6 \times$ His-fusion protein purification. For construction of His-STAT1, HisSTAT1Y701F, His-STAT1S727A plasmids, full-length STAT1 was first sub-cloned into the $\mathrm{pET}-32 \mathrm{Xa/LIC}$ vector (pET-32-STAT1). The mutant STAT1 plasmids ( $\mathrm{pET}$ 32-STAT1Y701F and PET-32-STAT1S727A) were then generated by using the QuickChange Site-Directed Mutagenesis Kit. These expression plasmids were then transformed to bacteria culture (200 ml) of Rosetta-gami 2(DE3) pLysS (Novagen, Schwalbach, Germany) and grew at $37^{\circ} \mathrm{C}$ until it reaches $\mathrm{OD}_{600} \sim 0.3$ before IPTG (Sigma-Aldrich) was added to a final concentration of $1 \mathrm{mM}$. After a further growing for $2 \mathrm{~h}$ at $37^{\circ} \mathrm{C}$, cells were resuspended in Bugbuster protein extraction reagent (Novagen) for protein extraction according to that described in the instruction manual. His-fusion proteins were purified by using the Ni-NTA His-Bind Resin (Novagen), eluted with $0.5 \mathrm{M}$ imidazole and dialyzed with BC-100 buffer.

In vitro kinase assay. For in vitro kinase assay, recombinant human STAT1 (Biosource, Camarillo, CA, USA) and STAT2 (Abcam, Cambridge, MA, USA) proteins or purified His-STAT1 protein and His-STAT1 mutant protein were incubated with active SGK1 (10-100 ng) (Upstate) in a total volume of $20 \mu \mathrm{l}$ kinase buffer $(25 \mathrm{mM}$ Tris- $\mathrm{HCl}, \mathrm{pH} 7.5,5 \mathrm{mM} \quad \beta$-glycerophosphate, $2 \mathrm{M}$ dithiothreitol, $0.1 \mathrm{mM} \mathrm{Na}_{3} \mathrm{VO}_{4}, 10 \mathrm{mM} \mathrm{MgCl}_{2}$, and $\left.8 \mu \mathrm{C}_{2}\left[\gamma_{-}{ }^{32} \mathrm{P}\right] \mathrm{ATP}\right)$ at $30^{\circ} \mathrm{C}$ for $30 \mathrm{~min}$. The reaction was stopped by addition of $5 \times$ SDS sample buffer and boiled. The mixture was then separated by $8 \%$ SDS-PAGE for autoradiography and western blot.

Drug injection to the brain and immunohistochemistry. For $A \beta$ injection to the brain, rats (Sprague-Dawley, male, 250-350 g bred at the Institute of Biomedical Sciences, Academia Sinica) were anesthetized with pentobarbital $(40 \mathrm{mg} / \mathrm{kg}$, ip) and placed on the stereotaxic instrument and $A \beta(30 \mu \mathrm{g} / \mu \mathrm{l})$ was injected to hippocampal CA1 area bilaterally at an injection volume of $0.8 \mu \mathrm{l}$ each side. The injection rate is $0.1 \mu / \mathrm{min}$. The coordinates for CA1 injection are: AP $3.5 \mathrm{~mm}$ posterior to the bregma, $\mathrm{ML} \pm 2.5 \mathrm{~mm}$ from the midline and DV $3.4 \mathrm{~mm}$ ventral to the skull surface. In another group of rats, $s g k S 78 D(1.6 \mu \mathrm{g})$ was transfected to $\mathrm{CA} 1$ area 4 days after $\mathrm{A} \beta$ injection. The other two groups of rats received $1 \%$ DMSO or $s g k S 78 D$ transfection alone. Before injection, $s g k S 78 D$ was diluted in $5 \%$ glucose to a stock concentration of $2.77 \mu \mathrm{g} / \mu \mathrm{l}$. Branched polyethyleneimine of $25 \mathrm{kDa}$ (Sigma-Aldrich) was diluted to $0.1 \mathrm{M}$ concentration in $5 \%$ glucose and added to the DNA solution. Immediately before infusion, $0.1 \mathrm{M}$ polyethyleneimine was added to reach a ratio of polyethyleneimine nitrogen per DNA phosphate equal to 10 . The mixture was vortexed for $30 \mathrm{~s}$ and allowed to equilibrate for $15 \mathrm{~min}$ at room temperature. The concentration and volume for DNA injection was $1.6 \mu \mathrm{g}$ in $0.8 \mu \mathrm{l}$ each side. Seven days after $A \beta$ injection (with or without $s g k S 78 D$ transfection), animals were again anesthetized with pentobarbital $(40 \mathrm{mg} / \mathrm{kg}, \mathrm{ip})$ and processed for immunohistochemistry as described earlier. ${ }^{37}$ Mouse anti-A $\beta$ antibody $(1: 250$, Santa Cruz) and mouse anti-NeuN antibody $(1: 1000$, Chemicon) were used. The secondary antibody used was goat antimouse antibody conjugated with Cy3. The hippocampal tissue was also stained with thioflavin $S\left(0.01 \%\right.$, Sigma-Aldrich) for visualization of $A \beta$ aggregates. ${ }^{45}$ Images were visualized and taken under a fluorescence microscope. In a separate group of animals, rats were killed 7 days after $A \beta$ treatment. Their brains were taken and cut with a brain slicer. The tissue session containing the hippocampal CA1 area was dissected out for western blot assays (for Figure 7a).

Statistical analysis. One-way analysis of variance and the post hoc NewmanKuel multiple comparison test were used for analyzing the results. Statistical significance was evaluated at the level of $P<0.05$ and $P<0.01$.

Acknowledgements. This work was supported by Grants from the National Science Council of Taiwan (NSC97-2321-B-001-003 and NSC98-2321-B-001-036) and research fund from the Institute of Biomedical Sciences, Academia Sinica, Taiwan.

1. De Strooper B, Annaert W. Proteolytic processing and cell biological functions of the amyloid precursor protein. J Cell Sci 2000; 113: 1857-1870.

2. Butterfield DA, Drake J, Pocernich C, Castegna A. Evidence of oxidative damage in Alzheimer's disease brain: central role for amyloid beta-peptide. Trends Mol Med 2001; 7: 548-554.

3. Dickson DW. Apoptotic mechanisms in Alzheimer neurofibrillary degeneration: cause or effect? J Clin Invest 2004; 114: 23-27.

4. Hardy J, Selkoe DJ. The amyloid hypothesis of Alzheimer's disease: progress and problems on the road to therapeutics. Science 2002; 297: 353-356. 
5. Lukiw WJ, Bazan NG. Survival signalling in Alzheimer's disease. Biochem Soc Trans 2006 34: $1277-1282$

6. Ohyagi Y, Asahara H, Chui DH, Tsuruta Y, Sakae N, Miyoshi K et al. Intracellular Abeta42 activates p53 promoter: a pathway to neurodegeneration in Alzheimer's disease. FASEB 2005; 19: 255-257.

7. Webster MK, Goya L, Ge Y, Maiyar AC, Firestone GL. Characterization of sgk, a novel member of the serine/threonine protein kinase gene family which is transcriptionally induced by glucocorticoids and serum. Mol Cell Biol 1993; 13: 2031-2040.

8. Lang F, Bohmer C, Palmada M, Seebohm G, Strutz-Seebohm N, Vallon V. (Patho)physiological significance of the serum- and glucocorticoid-inducible kinase isoforms. Physiol Rev 2006; 86: 1151-1178.

9. Park J, Leong ML, Buse P, Maiyar AC, Firestone GL, Hemmings BA. Serum and glucocorticoid-inducible kinase (SGK) is a target of the PI 3-kinase-stimulated signaling pathway. EMBO J 1999; 18: 3024-3033.

10. Kobayashi T, Cohen P. Activation of serum- and glucocorticoid-regulated protein kinase by agonists that activate phosphatidylinositide 3-kinase is mediated by 3-phosphoinositide-dependent protein kinase-1 (PDK1) and PDK2. Biochem $J$ 1999; 339: 319-328.

11. Meng F, Yamagiwa Y, Taffetani S, Han J, Patel T. IL-6 activates serum and glucocorticoid kinase via p38alpha mitogen-activated protein kinase pathway. Am J Physiol 2005; 289: C971-C981.

12. Brunet A, Park J, Tran H, Hu LS, Hemmings BA, Greenberg ME. Protein kinase SGK mediates survival signals by phosphorylating the forkhead transcription factor FKHRL1 (FOXO3a). Mol Cell Biol 2001; 21: 952-965.

13. Leong ML, Maiyar AC, Kim B, O'Keeffe BA, Firestone GL. Expression of the serumand glucocorticoid-inducible protein kinase, Sgk, is a cell survival response to multiple types of environmental stress stimuli in mammary epithelial cells. J Biol Chem 2003; 278 5871-5882.

14. Bowman T, Garcia R, Turkson J, Jove R. STATs in oncogenesis. Oncogene 2000; 19 2474-2488.

15. Horvath CM. STAT proteins and transcriptional responses to extracellular signals. Trends Biochem Sci 2000; 25: 496-502.

16. Ihle JN. The Stat family in cytokine signaling. Curr Opin Cell Biol 2001; 13: 211-217.

17. Decker T, Kovarik P. Serine phosphorylation of STATs. Oncogene 2000; 19: 2628-2637.

18. Battle TE, Frank DA. The role of STATs in apoptosis. Curr Mol Med 2002; 2: 381-392.

19. Kim HS, Lee MS. STAT1 as a key modulator of cell death. Cell Signal 2007; 19 : 454-465.

20. Stephanou A, Latchman DS. STAT-1: a novel regulator of apoptosis. Int J Exp Pathol 2003; 84: $239-244$

21. Stephanou A, Brar BK, Scarabelli TM, Jonassen AK, Yellon DM, Marber MS et al Ischemia-induced STAT-1 expression and activation play a critical role in cardiomyocyte apoptosis. J Biol Chem 2000; 275: 10002-10008.

22. Stephanou A, Scarabelli TM, Brar BK, Nakanishi Y, Matsumura M, Knight RA et al. Induction of apoptosis and Fas receptor/Fas ligand expression by ischemia/reperfusion in cardiac myocytes requires serine 727 of the STAT-1 transcription factor but not tyrosine 701. J Biol Chem 2001; 276: 28340-28347.

23. Stephanou A, Brar BK, Knight RA, Latchman DS. Opposing actions of STAT-1 and STAT-3 on the Bcl-2 and Bcl-x promoters. Cell Death Differ 2000; 7: 329-330.

24. Townsend PA, Scarabelli TM, Davidson SM, Knight RA, Latchman DS, Stephanou A STAT-1 interacts with p53 to enhance DNA damage-induced apoptosis. J Biol Chem 2004; 279: $5811-5820$.

25. Timofeeva OA, Plisov S, Evseev AA, Peng S, Jose-Kampfner M, Lovvorn HN et al. Serinephosphorylated STAT1 is a prosurvival factor in Wilms' tumor pathogenesis. Oncogene 2006; 25: 7555-7564.
26. Patterson SG, Wei S, Chen X, Sallman DA, Gilvary DL, Zhong B et al. Novel role of Stat1 in the development of docetaxel resistance in prostate tumor cells. Oncogene 2006; 25: 6113-6122.

27. Mori M, Burgess DL, Gefrides LA, Foreman PJ, Opferman JT, Korsmeyer SJ et al. Expression of apoptosis inhibitor protein Mcl1 linked to neuroprotection in CNS neurons. Cell Death Differ 2004; 11: 1223-1233.

28. Reynolds JE, Yang T, Qian L, Jenkinson JD, Zhou P, Eastman A et al. Mcl-1, a member of the Bcl-2 family, delays apoptosis induced by c-Myc overexpression in Chinese hamster ovary cells. Cancer Res 1994; 54: 6348-6352.

29. Kadowaki H, Nishitoh H, Urano F, Sadamitsu C, Matsuzawa A, Takeda K et al. Amyloid beta induces neuronal cell death through ROS-mediated ASK1 activation. Cell Death Differ 2005; 12: 19-24.

30. Aaronson DS, Horvath CM. A road map for those who don't know JAK-STAT. Science 2002; 296: 1653-1655.

31. Xia Z, Dickens M, Raingeaud J, Davis RJ, Greenberg ME. Opposing effects of ERK and JNK-p38 MAP kinases on apoptosis. Science 1995; 270: 1326-1331.

32. Hetman M, Gozdz A. Role of extracellular signal regulated kinases 1 and 2 in neuronal survival. Eur J Biochem/FEBS 2004; 271: 2050-2055.

33. Martin D, Salinas M, Lopez-Valdaliso R, Serrano E, Recuero M, Cuadrado A. Effect of the Alzheimer amyloid fragment Abeta(25-35) on Akt/PKB kinase and survival of PC12 cells. J Neurochem 2001; 78: 1000-1008.

34. Zhang L, Cui R, Cheng X, Du J. Antiapoptotic effect of serum and glucocorticoid-inducible protein kinase is mediated by novel mechanism. Cancer Res 2005; 65: 457-464.

35. Lin CL, Chen TF, Chiu MJ, Way TD, Lin JK. Epigallocatechin gallate (EGCG) suppresses beta-amyloid-induced neurotoxicity through inhibiting c-Abl/FE65 nuclear translocation and GSK3beta activation. Neurobiol Aging 2009; 30: 81-92.

36. Ahmad KA, Wang G, Unger G, Slaton J, Ahmed K. Protein kinase CK2-a key suppressor of apoptosis. Adv Enzyme Regul 2008; 48: 179-187.

37. Chao CC, Chiang $\mathrm{CH}, \mathrm{Ma}$ YL, Lee EH. Molecular mechanism of the neurotrophic effect of GDNF on DA neurons: role of protein kinase CK2. Neurobiol Aging 2006; 27: 105-118.

38. Sato N, Kamino K, Tateishi K, Satoh T, Nishiwaki Y, Yoshiiwa A et al. Elevated amyloid beta protein(1-40) level induces CREB phosphorylation at serine-133 via p44/42 MAP kinase (Erk1/2)-dependent pathway in rat pheochromocytoma PC12 cells. Biochem Biophys Res Commun 1997; 232: 637-642.

39. Ramsauer K, Sadzak I, Porras A, Pilz A, Nebreda AR, Decker T et al. p38 MAPK enhances STAT1-dependent transcription independently of Ser-727 phosphorylation. Proc Natl Acad Sci USA 2002; 99: 12859-12864

40. Yaffe MB, Leparc GG, Lai J, Obata T, Volinia S, Cantley LC. A motif-based profile scanning approach for genome-wide prediction of signaling pathways. Nat Biotechnol 2001; 19: 348-353.

41. Marin O, Meggio F, Sarno S, Cesaro L, Pagano MA, Pinna LA. Tyrosine versus serine/ threonine phosphorylation by protein kinase casein kinase-2. A study with peptide substrates derived from immunophilin Fpr3. J Biol Chem 1999; 274: 29260-29265.

42. Boulton TG, Nye SH, Robbins DJ, Ip NY, Radziejewska E, Morgenbesser SD et al. ERKs: a family of protein-serine/threonine kinases that are activated and tyrosine phosphorylated in response to insulin and NGF. Cell 1991; 65: 663-675.

43. Resende R, Ferreiro E, Pereira C, Resende de Oliveira C. Neurotoxic effect of oligomeric and fibrillar species of amyloid-beta peptide 1-42: involvement of endoplasmic reticulum calcium release in oligomer-induced cell death. Neuroscience 2008; 155: 725-737.

44. Lee HK, Kumar P, Fu Q, Rosen KM, Querfurth HW. The insulin/Akt signaling pathway is targeted by intracellular beta-amyloid. Mol Biol Cell 2009; 20: 1533-1544.

45. Stephan A, Laroche S, Davis S. Generation of aggregated beta-amyloid in the rat hippocampus impairs synaptic transmission and plasticity and causes memory deficits. J Neurosci 2001; 21: 5703-5714.

\section{Supplementary Information accompanies the paper on Cell Death and Differentiation website (http://www.nature.com/cdd)}

